\title{
The Ribosome as a Switchboard for Bacterial Stress Response
}

\author{
He Cheng-Guang and Claudio Orlando Gualerzi ${ }^{*}$ \\ College of Life Sciences, JiLin Agricultural University, Changchun, China
}

As free-living organisms, bacteria are subject to continuous, numerous and occasionally drastic environmental changes to which they respond with various mechanisms which enable them to adapt to the new conditions so as to survive. Here we describe three situations in which the ribosome and its functions represent the sensor or the target of the stress and play a key role in the subsequent cellular response. The three stress conditions which are described are those ensuing upon: a) zinc starvation; b) nutritional deprivation, and c) temperature downshift.

\section{OPEN ACCESS}

Edited by:

Stefano Marzi,

UPR9002 Architecture et Réactivité

de l' arN, France

Reviewed by:

Nora Vazquez-Laslop,

University of Illinois at Chicago,

United States

Tanel Tenson,

University of Tartu, Estonia

*Correspondence: Claudio Orlando Gualerzi scholzcarl@yahoo.de

${ }^{\dagger}$ Present address: Claudio Orlando Gualerzi, Retired, Berlin, Germany

Specialty section: This article was submitted to Microbial Physiology and Metabolism,

a section of the journal

Frontiers in Microbiology

Received: 19 October 2020 Accepted: 03 December 2020 Published: 08 January 2021

Citation:

Cheng-Guang $\mathrm{H}$ and Gualerzi $\mathrm{CO}$ (2021) The Ribosome as a Switchboard for Bacterial Stress Response.

Front. Microbiol. 11:619038. doi: 10.3389/fmicb.2020.619038
Keywords: protein paralogs, translational bias, Cold shock proteins, translation initiation factors, ppGpp

\section{INTRODUCTION}

The ribosome is a gigantic ribozyme entirely devoted to decoding the genetic message and to the synthesis of proteins. These activities ultimately represent the main and most energy demanding functions of bacterial cells whose life mission is to accumulate proteins, grow and proliferate by dividing upon having reached a critical mass. The function of bacterial ribosomes in the initiation, peptide bond formation, elongation and termination steps of translation have been described in review articles, e.g., Rodnina et al. (2007), Korostrelev (2011), and Gualerzi and Pon (2015).

In addition to playing this vital role, ribosomes and, more generally, ribosomal functions are objects and actors in a large number of regulatory circuits. In this article we focus on the role played by ribosomes and the translational machinery in the cellular response to three different types of stress, namely zinc starvation, nutritional deprivation and cold shock. The common denominator of these three stress situations is the central role played by the translational apparatus in the cellular responses, whereas the quite different mechanisms by which it operates offer a wide range of the diverse ways by which ribosomes allow the cell to cope with various environmental cues.

\section{Participation of the Ribosome in Cellular Zinc Homeostasis}

Numerous vital processes such as DNA replication, transcription, translation, electron transfer, and alleviation of oxidative stress, require some transition metals as cofactors. Furthermore, bacterial pathogens must compete with their hosts for limited metal availability resulting from nutritional immunity of the host which restricts metal bioavailability (Kehl-Fie and Skaar, 2010; Cerasi et al., 2013; Becker and Skaar, 2014). On the other hand, because an excess of these metals may have toxic effects, bacteria have evolved a number of mechanisms which ensure metal homeostasis, allowing them to thrive between metal scarcity and toxicity.

Zinc is probably the most important among the essential metal ions $\left(\mathrm{Fe}^{2+}, \mathrm{Mn}^{2+}, \mathrm{Cu}^{2+}\right.$, and $\mathrm{Ni}^{2+}$ ), being present in many proteins involved in fundamental processes. In fact, zinc is a structural or catalytic cofactor of many enzymes, including the metallo-beta-lactamases which inactivate beta-lactam antibiotics playing an important role in infections caused by multi-drug resistant bacteria (Kim et al., 2011, 2013). One of the enzymes whose activity requires zinc is GTP 
cyclohydrolase I (GCYH-I), the first enzyme in the pathway of tetrahydrofolate (THF) biosynthesis. Thus, as detailed below, zinc availability can affect THF levels thereby impacting on the translational activity of the cell.

$\mathrm{Zn}^{2+}$ is used because of its peculiar and favorable chemical properties and during catalysis behaves like a Lewis acid, accepting electron pairs or attracting/stabilizing negative charges of substrates (Andreini et al., 2008).

Approximately 6\% of Escherichia coli proteins are able to bind zinc (Andreini et al., 2008) and proteomic studies have shown that several ribosomal proteins (i.e., L2, L13, S2, S15, S16, and S17) can bind Zn (Katayama et al., 2002). Furthermore, another biophysical study (Hensley et al., 2012) showed that in E. coli eight $\mathrm{Zn}$ equivalents are bound to ribosomal proteins S2, S15, S16, S17, L2, L13 and to the highly conserved 50S proteins L31 and L36 (Wada, 1986a,b; Wada and Sako, 1987) which contain a $\mathrm{Zn}$ ribbon motif consisting of four cysteines (histidines in some cases) (Makarova et al., 2001; Panina et al., 2003). As detailed below, these proteins play an important role upon $\mathrm{Zn}$ starvation, acting as cellular $\mathrm{Zn}^{2+}$ reservoirs (Akanuma et al., 2006).

Protein L31 bridges the $30 \mathrm{~S}$ head and central protuberance of the $50 \mathrm{~S}$ subunit and, by virtue of its dynamic nature, maintains its interactions with both subunits during ribosome ratcheting movement as its linker region switches from an extended to a kinked conformation (Fischer et al., 2015). During stationary phase, under the influence of the ribosome modulation factor, L31 also plays a role in $100 \mathrm{~S}$ (dimers of $70 \mathrm{~S}$ ribosomes) formation (Wada et al., 1990). In ribosomes lacking L31, peptide elongation is slower, subunit association weakened and no $100 \mathrm{~S}$ are formed. Furthermore, although L31 is not essential for survival, strains lacking this protein grow very slowly and their ribosomes are $40 \%$ less active than those having one copy of L31 (Ueta et al., 2017).

Protein L36, the smallest, most basic and widely conserved ribosomal protein belongs to the late ("fifth") assembly group identified by mass spectrometry (Chen and Williamson, 2013), being involved in the late steps of $50 \mathrm{~S}$ subunit assembly upon binding to $23 \mathrm{~S}$ rRNA (Urlaub et al., 1995). Together with the RlmE-dependent U2552 2'-O-methylation, L36 promotes the association between helices 92 and 71 resulting in the structural organization of $23 \mathrm{~S}$ rRNA (Arai et al., 2015). Cells lacking L36 are viable but between 30 and $42^{\circ} \mathrm{C}$ display a $50 \%$ growth retardation compared to wt cells (Maeder and Draper, 2005). Despite displaying normal 30S-50S association and 100 S formation during stationary phase, ribosomes lacking L36 have a $30 \%$ reduced translational activity.

Interestingly, in E. coli there are two proteins, YkgM and $\mathrm{YkgO}$, which are paralogs of $\mathrm{L} 31$ and L36, respectively. YkgM (87 residues) is 17 residues longer than $\mathrm{L} 31$ while $\mathrm{YkgO}$ is eight amino acids longer than L36 (46 vs 38 residues). Unlike L31 and L36, these paralogs do not contain a Zn-binding motif. Paralogs of L31 and L36 lacking zinc-binding sites have been detected in many gamma-proteobacteria and in Streptomyces. In E. coli L31 and its paralog YkgM are encoded by rpmE and $y \mathrm{kgM}$, respectively, while $\mathrm{L} 36$ and its paralog $\mathrm{YkgO}$ are encoded by $r p m J$ and $y \mathrm{kgO}$, respectively. As illustrated in Figure 1, these genes are Zn-regulated insofar as only rpmE and rpmJ encoding L31 and
L36 are expressed in the presence of zinc, whereas $y \mathrm{kgM}$ and $y \mathrm{kgO}$, which encode the paralogs, are expressed only when zinc is limiting. $Y \mathrm{kgM}$ and $y \mathrm{kgO}$ are present in the same operon whose transcription is inhibited by the Zur repressor, a member of the Fur family of metal-responsive regulators. In the presence of zinc a dimer of Zur dimers recognizes and binds a 13 bp palindrome with a three-base spacer (RNNNYxxxRNNNY) (Gilston et al., 2014). However, Zur becomes inactivated upon zinc depletion and zinc uptake genes of the $\mathrm{ABC}$ family of transporters such as AdcABC of Gram positive and ZnuABC of Gram-negative bacteria are derepressed (Panina et al., 2003; Hantke, 2005; Graham et al., 2009; Hemm et al., 2010; Velasco et al., 2018). Likewise, transcription of the $y k g M-y k g O$ operon is induced and YkgM and YkgO are expressed (Graham et al., 2009; Hemm et al., 2010) and replace their paralogs L31 and L36 upon binding to the same ribosomal site (Ueta et al., 2020). Ribosomes containing one copy of $\mathrm{YkgM}$ and no L31 are functionally equivalent to wild-type ribosomes which contain one copy of L31 as far as subunits association, in vitro translation and $100 \mathrm{~S}$ formation are concerned. Furthermore, mutants carrying these ribosomes grow like wt cells indicating that $\mathrm{YkgM}$ is functionally identical to L31 and that the zinc bound to L31 is not involved in translational processes.

Protein L36 contacts the 23S rRNA at sites which are relevant for the peptidyl transferase center (H89 and H91) and for elongation factor binding (H42, the stem that binds L10/L12 and $\mathrm{H} 95$ in the four-helix junction containing the sarcin-ricin loop). The tertiary interactions between helices 89,91 , and 95 are disrupted in ribosomes lacking L36. In spite of this, rpmJ is not essential for growth in L-broth at $37^{\circ} \mathrm{C}$. However, whereas cells expressing the paralog $\mathrm{YkgO}$ display wild-type growth, cells lacking rpmJ grow more slowly indicating that L36 can be functionally replaced by its paralog $\mathrm{YkgO}$, at least as far as growth is concerned (Maeder and Draper, 2005; Baba et al., 2006).

All evidence gathered so far indicates that the presence of zinc in the two ribosomal proteins is not necessary for the translational function of the ribosome because L31 and L36 can be replaced by the functionally equivalent non-Zn-containing paralogs YkgM and YkgO. Thus, it can be surmised that L31 and L36 are related to $\mathrm{Zn}$ storage and provision. In fact, under conditions of zinc starvation, the non-Zn containing paralogs of L31 and L36 are expressed and incorporated into ribosomes in place of the original Zn-containing ribosomal proteins. Under conditions of $\mathrm{Zn}$ shortage, instead of using all available zinc, the proteins containing the $\mathrm{Zn}$ ribbon act as $\mathrm{Zn}$ suppliers, being excluded from the ribosomes and degraded so that $\mathrm{Zn}$ is released into the cytoplasm for utilization by other vitally important zinc-binding proteins such as DNA polymerase, primase, etc. (Panina et al., 2003; Nanamiya et al., 2004; Gabriel and Helmann, 2009) (Figure 1).

As to the efficacy of this system, it should be considered that the number of ribosomes, each containing one copy of L31 and L36, is thousands fold higher than that of other cellular $\mathrm{Zn}$ requiring proteins and that the $\mathrm{Zn}$ concentration needed by the cell is very low. Indeed, the concentration of readily exchangeable zinc measured in E. coli cells was found to vary significantly depending upon the extracellular zinc concentration, but to be 


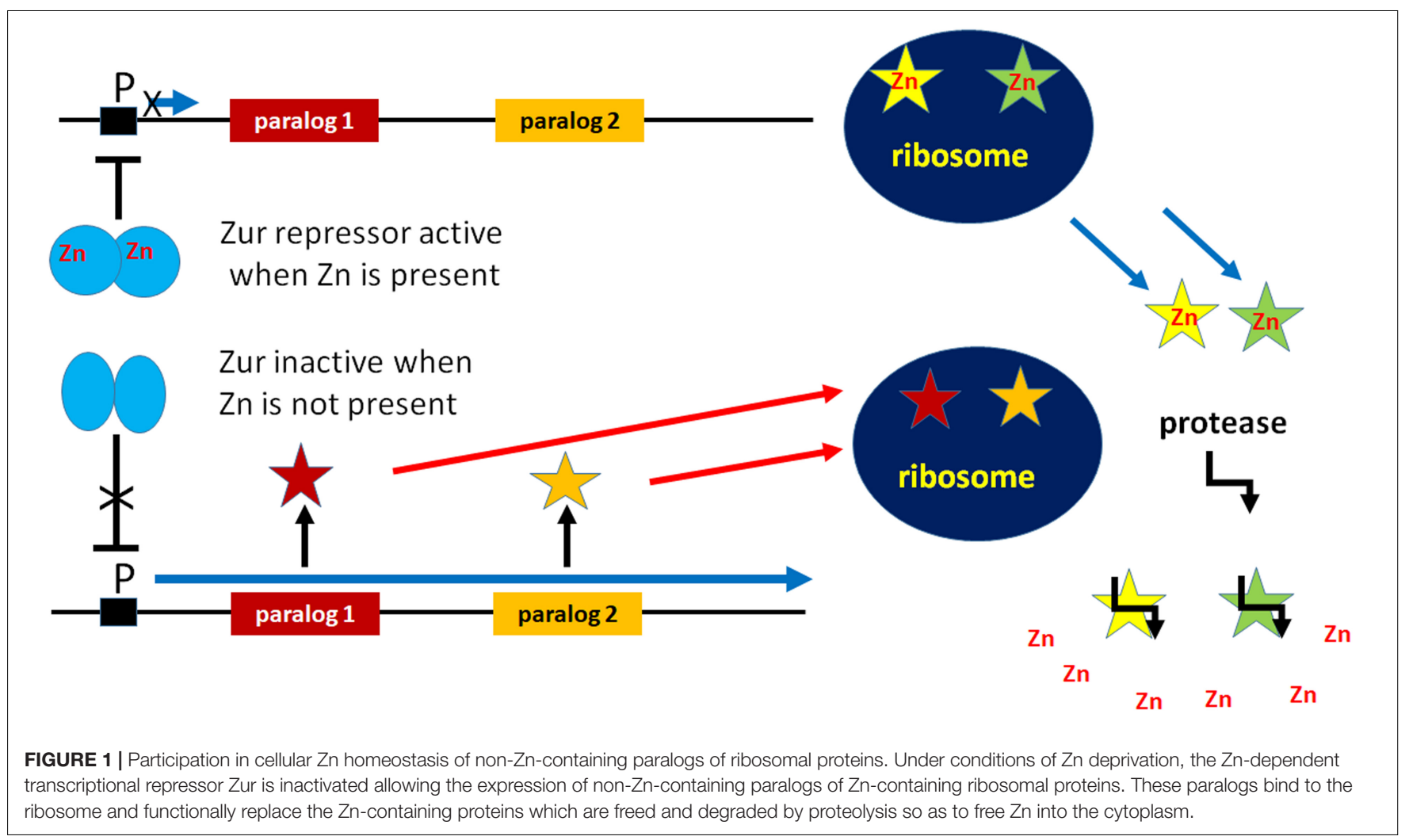

in the pmolar range (i.e., in average ca. $2 \times 10^{-11} \mathrm{M}$ ) (Outten and O'Halloran, 2001; Wang et al., 2011).

A situation similar to that just described for E. coli is likely common to other bacterial species, although other $\mathrm{Zn}$-binding ribosomal proteins, such as L33 and S14, might be involved. Indeed, several bacterial genomes encode paralogs of ribosomal proteins $\mathrm{L} 36, \mathrm{~L} 33, \mathrm{~L} 31$, and S14 which lack the Zn-ribbon and are expressed upon zinc starvation. When L31-paralogs are not present, like in some Staphylococci, Streptococci, Listeriae etc. the genome encodes L33 and S14 paralogs. Remarkably, the Bacillus subtilis genome encodes paralogs of all these proteins (i.e., L36, L33, L31, and S14) (Panina et al., 2003).

In conclusion, it appears clear that bacterial cells respond to zinc shortage with inactivation of the $\mathrm{Zn}$-dependent transcriptional repressor Zur, resulting in the expression not only of genes encoding high-affinity $\mathrm{Zn}$ transporters, such as ZnuABC, but also of the non- $\mathrm{Zn}$ containing paralogs of ribosomal proteins L31, L33, L36, and S14 which participate in maintaining cellular Zn homeostasis (Hantke, 2005; Moore and Helmann, 2005).

As mentioned above, variations of $\mathrm{Zn}$ availability can affect one-carbon (1-C) metabolism and, in turn, translational activity of the cell. In fact, the first enzyme of the pathway leading to THF biosynthesis is the Zn-dependent GTP cyclohydrolase I (GCYHI). In addition to being involved in transferring 1-C units to purines, thymidylate, pantothenate, glycine and serine, THF is involved in the synthesis of methionine and formylmethionyltRNA which are essential elements of the translation initiation pathway. The Zn-dependent GCYH-I catalyzes the conversion of GTP to 7,8-dihydroneopterin triphosphate (Figure 2A) in a complex reaction that begins with hydrolytic opening of the purine ring at C-8 of GTP to generate an $\mathrm{N}$-formyl intermediate. The role of $\mathrm{Zn}^{2+}$ in the first reaction step consists in the activation of a water molecule for nucleophilic attack at C8 (Green et al., 1996). While GCYH-I is encoded by folE in E. coli, another type of GCYH-I enzyme, named GCYH-IB, has been detected in approximately $25 \%$ of the bacterial species whose genomes have been sequenced. This enzyme, encoded by folE2, does not require $\mathrm{Zn}$ but can be activated by a variety of other divalent cations (Sankaran et al., 2009). Although the majority (i.e., ca. 2/3) of bacteria possess either a folE (like E. coli) or folE2, a sizable minority of bacteria, B. subtilis among them, possesses both genes; it is interesting that whereas folE is expressed in the presence of sufficient levels of $\mathrm{Zn}$, folE2 is repressed by the $\mathrm{Zn}^{2+}$-dependent Zur repressor and is expressed under $\mathrm{Zn}$-limiting conditions allowing folate biosynthesis even during $\mathrm{Zn}$ starvation. This underscores both importance of systems ensuring zinc homeostasis and the vital role played by THF in the cells (Figure 2B).

\section{Central Role of Ribosomes in the Response to Nutritional Stress}

Translation initiation is generally regarded as being rate limiting for bacterial protein synthesis and therefore represents the step which is preferentially and more frequently subjected to post transcriptional regulation (McCarthy and Gualerzi, 1990).

In addition to the energetic costs connected with synthesis and assembly of the translational apparatus, protein synthesis 


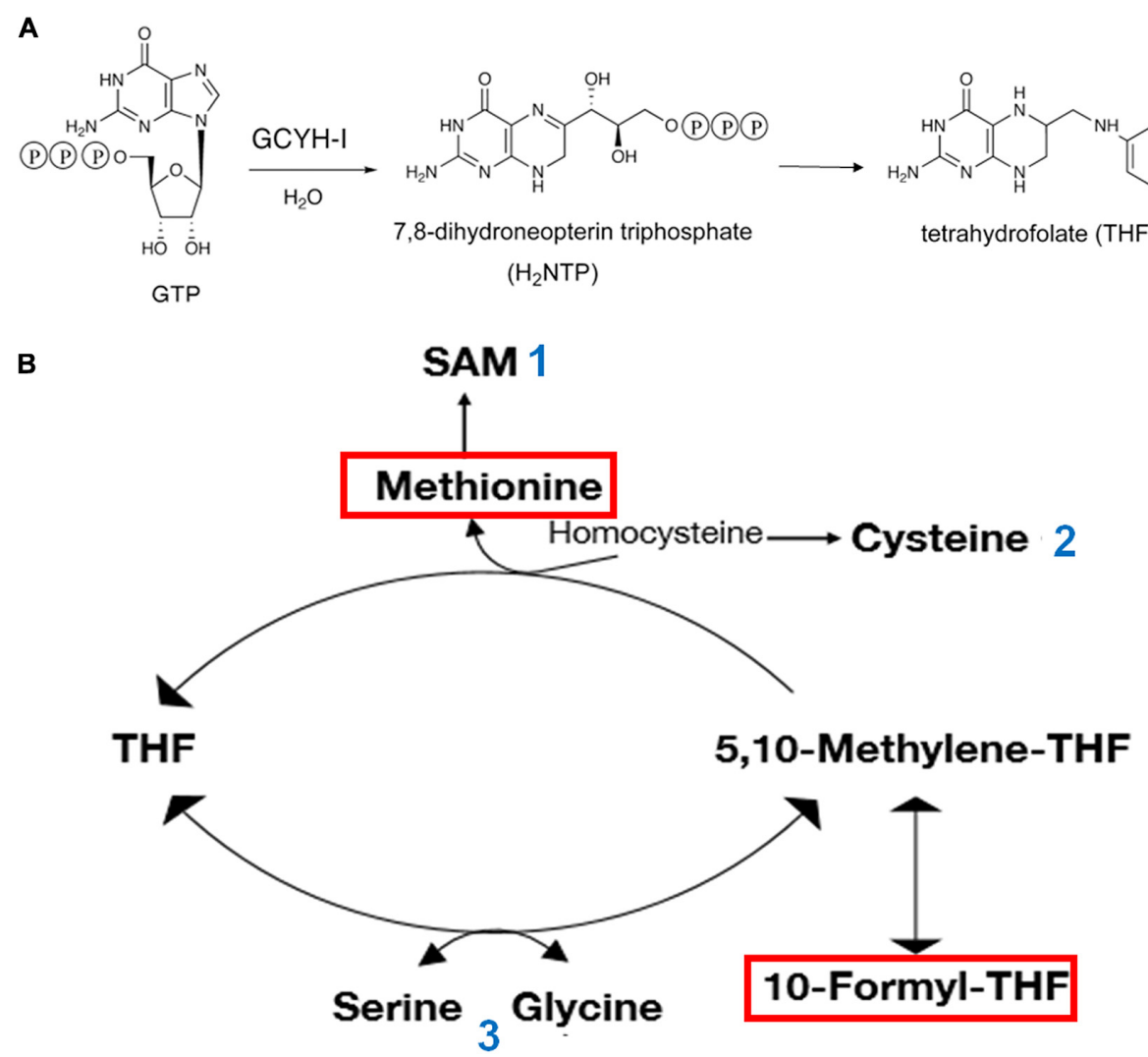

FIGURE 2 | Involvement of Zn and GTP in THF synthesis and central role of 1-C metabolism in translation initiation. (A) The Zn-dependent enzyme GTP cyclohydrolase I (GCYH-I) catalyzes the conversion of GTP to 7,8-dihydroneopterin triphosphate which in turn is converted to 6-hydroxymethyl-dihydropterin by dihydroneopterin aldolase (FolB) and finally to THF through the consecutive action of enzymes FolK, FolP, FolC, and FolA. (B) The amino acid methionine, used for the aminoacylation of methionine-specific elongator and initiator tRNAs and 10-formyl-THFMethyl, which transfers a formyl group to the $\alpha-\mathrm{NH}_{2}$ group of methionine in Met-tRNA $f_{\text {fMet }}$ are boxed in red. Additional molecules playing a role in the translational apparatus are shown. The numbers next to these molecules indicate their participation as: 1 - methyl donor for all types of RNA molecules and proteins; ribosyl donor for queuosine modification of the first anticodon position of tRNAs specific for His, Asp, Asn, and Tyr; synthesis of polyamine; 2 - aminoacylation of tRNA specific for Cys; thio-modification of tRNAs; 3 - aminoacylation of tRNAs specific for Ser and Gly.

itself uses a considerable share of the cellular energy pool as large amounts of ATP and GTP are required to activate amino acids for tRNA aminoacylation and to support the activity of the translational GTPases (IF2, EF-Tu, EF-G, and RF3). To prevent superfluous use of energy when nutrients are in scarce supply, translation must be tightly regulated at the initiation step which depends upon the metabolic state of the cell, upon 1-C metabolism and upon the nature and concentration of guanine nucleotides.

Under optimal growth conditions, GTP is present in millimolar concentrations in the cell, whereas the very low levels of the alarmones (p)ppGpp (guanosine $3^{\prime}$-diphosphate, $5^{\prime}$ triphosphate) and ppGpp (guanosine $3^{\prime}, 5^{\prime}$-bispyrophosphate) play essential roles in various aspects of bacterial physiology, modulating growth rate, general metabolism and GTP homeostasis (Potrykus and Cashel, 2008; Potrykus et al., 2011; Kriel et al., 2012; Hauryliuk et al., 2015; Fernández-Coll and Cashel, 2020). However, under a variety of stress conditions, including starvation for an essential amino acid, which gives rise to a "stringent response," many bacteria synthesize large amounts of these alarmones (Figure 3). During stringent response, the ppGpp concentration increases ca. 100 -fold reaching $1 \mathrm{mM}$ in E. coli but substantially less in B. subtilis (Kriel et al., 2012). The accumulation of (p)ppGpp has drastic effects on various vital functions of the cell (Figure 3 ) and in some cases, like in B. subtilis (but not in E. coli), is accompanied by a substantial reduction of the cellular level of GTP. In turn, a reduction of GTP levels affects the 1-C metabolism, THF synthesis and ultimately translation (Figure 2).

Synthesis of (p)ppGpp and ppGpp entails the transfer of the ATP pyrophosphate to either GDP or GTP (Chatterji and Ojha, 2001) and occurs through the action of RelA/SpoT homologue (RSH) proteins which are highly conserved in bacteria and consist either of a single domain or of multiple domains as in E. coli. RelA and SpoT have a similar architecture (Figure 4); the catalytic module responsible for (p)ppGpp synthesis is located in the $N$-terminal (NTD) region and is more active in RelA than in SpoT whereas the module responsible for (p)ppGpp hydrolysis is active in SpoT and inactive in RelA (Atkinson et al., 2011). The CTD region of RelA has regulatory functions, as detailed below. 


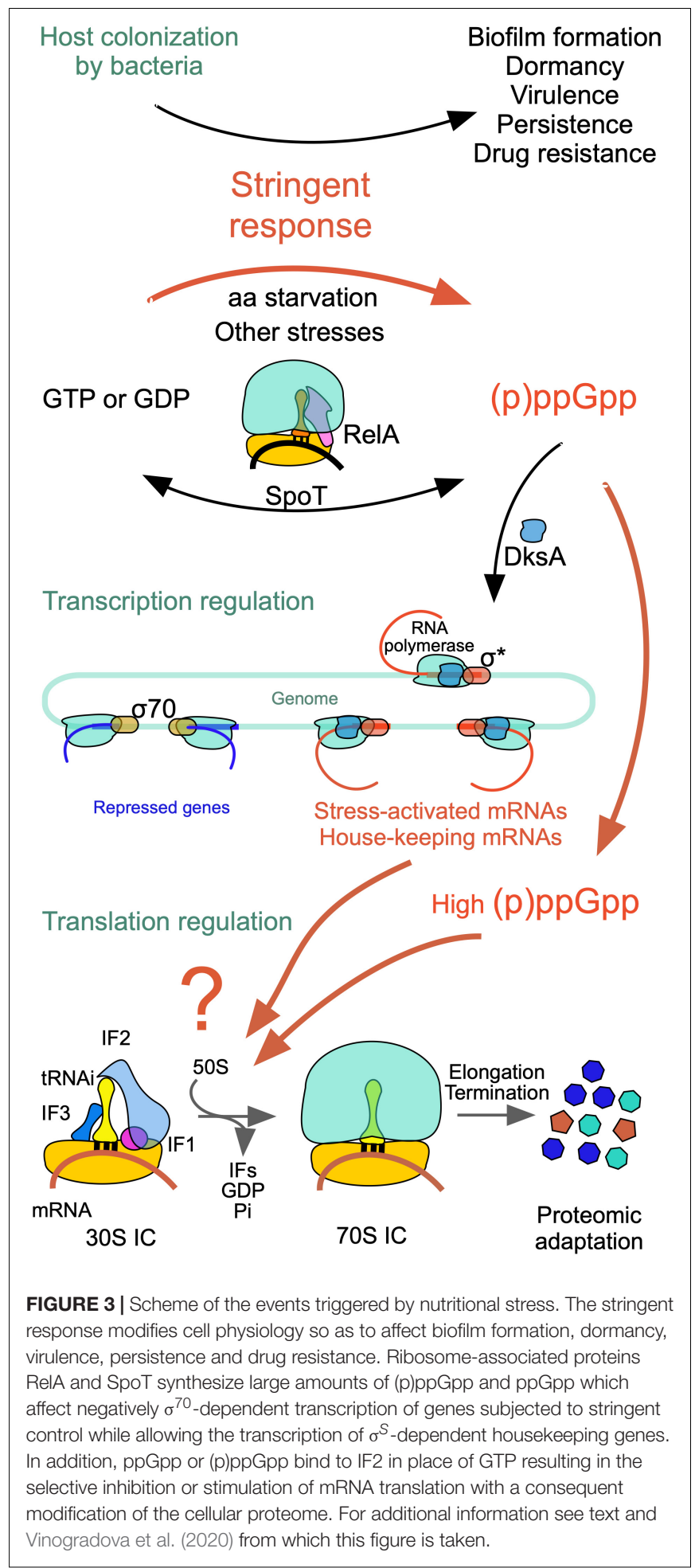

Protein RelA associates with the 50S subunit and its function is partially dependent upon ribosomal protein L11 (Ramagopal and Davis, 1974; Gropp et al., 2001; Yang and Ishiguro, 2001; Wendrich et al., 2002). The CTD is buried inside the ribosome while the catalytic region is exposed to the cytoplasm. Sensing the binding of an uncharged cognate tRNA to the A-site of stalled ribosomes promotes the stabilization of the TGS domain (Figure 4) in a position in which the uncharged CCA $3^{\prime}$ end of tRNA can fit in a pocket. Synthesis of (p)ppGpp is triggered when the contact between the NTD and ribosome is stabilized by a contact of the synthetase domain with the tip of the 16S rRNA spur, while the non-functional hydrolase domain is bound near the 23S rRNA sarcin-ricin loop (Arenz et al., 2016; Brown et al., 2016; Loveland et al., 2016; Winther et al., 2018).

Unlike RelA, SpoT is a bifunctional protein responsible for both synthesis and hydrolysis of (p)ppGpp. Synthesis of (p)ppGpp by SpoT is triggered by a variety of cellular stress conditions (Figure 3) whereas ribosomes and uncharged tRNA inhibit its hydrolytic activity (Richter, 1980). In spite of some past controversy concerning the SpoT location, more recent data have shown that SpoT interacts with the ribosome-associated GTPase CgtA and is also associated with a pre-50S particle independent from CgtA. In fact, CgtA promotes (p)ppGpp hydrolysis by SpoT on the ribosome whereas its loss from the ribosome is necessary for maximal (p)ppGpp accumulation under stress conditions (Jiang et al., 2007).

The increase in the ppGpp concentration has pleiotropic effects, modulating expression, stability, oligomerization and activity of a variety of proteins and regulatory RNAs, inhibiting DNA synthesis and causing cell cycle arrest (Magnusson et al., 2005; Maciąg-Dorszyńska et al., 2013 and references therein) (Figure 3). Effects of ppGpp and pppGpp on transcription are also well documented (Potrykus and Cashel, 2008; Potrykus et al., 2011). Both alarmones bind in a small, positively charged cavity on the outer surface of RNA polymerase, at the interface between the $\beta^{\prime}$ (which binds the guanosine) and $\omega$ subunits (which binds both pyrophosphates). Because the binding site is located far away (i.e., $30 \AA$ ) from the polymerization center, regulation of the RNAP activity by ppGpp is believed to depend upon an allosteric mechanism (Mechold et al., 2013; Zuo et al., 2013) thereby regulating promoter selection (Chatterji et al., 1998; Toulokhonov et al., 2001; Magnusson et al., 2005; Paul et al., 2005). This binding results in the selective transcriptional inhibition of genes subjected to stringent control such as those encoding rRNA and tRNA as well as genes required for growth and proliferation while allowing expression of genes which encode products enabling physiological adaptations and ultimately cell survival, such as amino acid biosynthesis genes (Potrykus and Cashel, 2008) (Figure 3). The basis for the selective silencing of some genes, while other genes are expressed, can be found at the level of both transcription and translation, as will be detailed below.

In addition to their direct participation in the stringent response as carriers of RelA and SpoT, which are responsible for ppGpp accumulation, the ribosomes play additional roles in the cellular response to nutritional stress. In fact, a shortage of carbon, nitrogen and sulfur can drastically affect ribosomal functions during translation initiation.

Indeed, the use of methionine as the $N$-terminal amino acid of nascent polypeptides and the modification of its $\alpha-\mathrm{NH}_{2}$ group with a formyl group derived from 10-formyl-tetrahydrofolate tightly connect translation initiation to folic acid-mediated 1-C metabolism whose main outputs are methionine and AdoMet. 


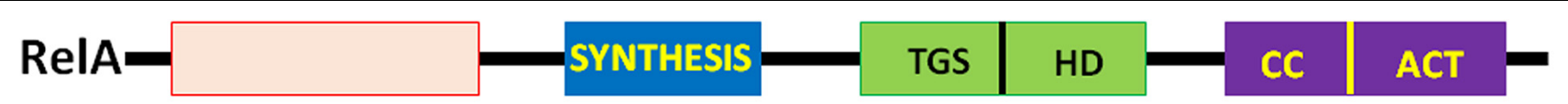
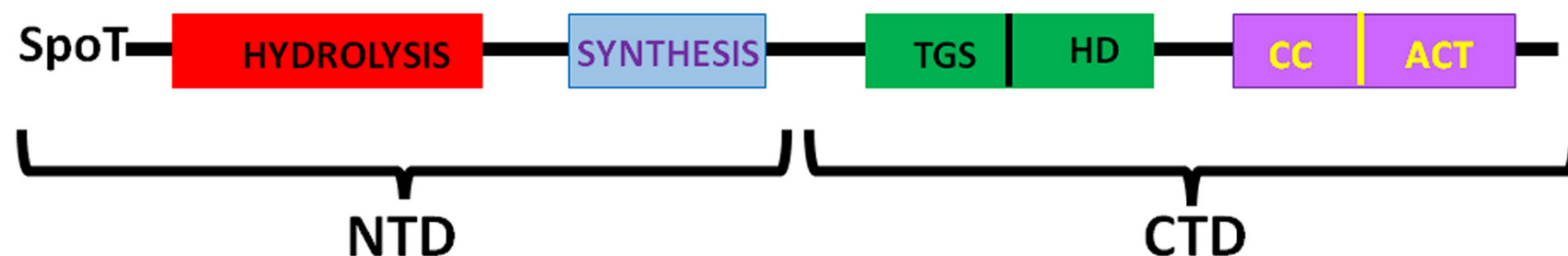

FIGURE 4 | Schematic representation of the six-domain structure of E. coli RelA and SpoT. From left (NTD) to right (CTD) the proteins contain: the (p)ppGpp hydrolysis domain active in SpoT and inactive in RelA; the (p)ppGpp synthesis (SYNTH) domain, more active in RelA than in SpoT; the ThrRS, GTPase, and SpoT (TGS) domain; the helical domain (HD); the conserved cysteines domain (CC) and the Aspartokinase, Chorismate mutase and TyrA domain (ACT). Additional details can be found in the text and in Atkinson et al. (2011).

In turn, methionine is a major donor of $1-\mathrm{C}$ units in the cell and plays an essential role in a large number of methylations. Furthermore, together with cysteine, methionine is the only sulfur containing amino acid.

As mentioned above, protein synthesis initiates with a methionine residue esterified to the $3^{\prime}$ acceptor end of a special tRNA molecule (i.e., tRNA $_{\text {fmet }}$ ). The peculiar characteristics of this tRNA are recognized by a specific transformylase which transfers a formyl group from 10-formyl-tetrahydrofolate to the $\alpha-\mathrm{NH}_{2}$ group of methionine to yield initiator fMet-tRNA $f$ Met (Mangroo et al., 1995; RajBhandary and Chow, 1995; Mechulam et al., 1999; Mayer et al., 2001). In turn, fMet-tRNA fMet $_{\text {is }}$ used to initiate protein synthesis in the majority of the cases. As a result, formyl-methionine is almost invariably the $N$-terminal amino acid of bacterial nascent peptides. A possible exception could be the case of Firmicutes which may initiate protein synthesis in the absence of folate-mediated formylation of methionyl-tRNA ${ }_{f M e t}$ when grown in a medium supplemented with all the metabolites directly associated with 1-C metabolism (e.g., serine, glycine, purines, thymine, and pantothenate) (Samuel et al., 1970).

FMet-tRNA $_{f M e t}$ is recognized and bound by the $C$-terminal domain of IF2, the largest of the three initiation factors (Guenneugues et al., 2000; Spurio et al., 2000), and recruited to the ribosomal $\mathrm{P}$ site by the ribosome-bound factor (Milon et al., 2010). IF2 is a G protein whose G2 domain (Wienk et al., 2012) binds and hydrolyzes GTP in the presence of aliphatic alcohols or upon activation by its interaction with the ribosomal GTPase-associated center consisting of the 23S rRNA sarcinricin loop and ribosomal protein L7/L12 (Gualerzi et al., 1991; Severini et al., 1991; La Teana et al., 2001; Diaconu et al., 2005; Koch et al., 2015; Carlson et al., 2017). In addition to GTP, also GDP and the alarmone ppGpp can bind to the same site of IF2 (Figure 5A) with similar or somewhat greater affinities. However, unlike GTP, which strengthens the IF2 interaction with the $30 \mathrm{~S}$ subunit and stimulates the functions of the factor, GDP interferes with these activities whereas ppGpp severely inhibits them (Pon et al., 1985; Fabbretti et al., 2012) (Figure 5B). In fact, it has been shown that ppGpp inhibits translation by blocking the IF2-dependent formation of the 30 S initiation complex (30SIC).
Although ppGpp can also bind to elongation factors EF-G and EF-Tu, translation inhibition was shown to be selectively caused by inhibition of the initiation factor (Milon et al., 2006). This conclusion is in full agreement with the finding that ppGpp has hardly any effect on the activity of EF-Tu (Pingoud et al., 1983; Rojas et al., 1984) and that ppGpp displays a $\sim 5$-fold higher affinity for IF2 than for EF-G suggesting that "during stringent response in vivo, IF2 is more responsive to ppGpp than to EF-G" (Mitkevich et al., 2010).

Based on these findings it was suggested that a fundamental raison d'être of the guanosine nucleotide binding site of IF2 is to confer upon this factor the properties of a metabolic sensor capable of causing a feedback inhibition by blocking de novo protein synthesis when the nutritional conditions become unfavorable (Milon et al., 2006) (Figure 5B).

Selective inhibition by ppGpp of the initiation functions of IF2, such as 30SIC formation and docking of the 50S subunit to yield a 70SIC, was confirmed in a recent study in which it was shown that inhibition of IF2 activity by ppGpp occurs also during cellular entry into quiescence (Diez et al., 2020).

As mentioned above, the stringent response entails not only the silencing of some genes whose expression would be detrimental under nutritional stress, but also the activation of other genes which allow cells to cope with the unfavorable situation. This implies that both transcription and translation are not indiscriminately inhibited (Figure 3). Accordingly, a recent study, while confirming the previous finding that ppGppbound IF2 inhibits translation by shifting to the left the $30 \mathrm{~S}$ pre-IC $\leftrightarrows 30$ SIC equilibrium (Milon et al., 2006), showed that ppGpp does not inhibit the translation of all mRNAs but instead allows the synthesis of a select group of proteins (Vinogradova et al., 2020). This is possible because the affinity of GTP for IF2 was shown to depend upon the type of mRNA present in the $30 \mathrm{~S}$ pre-IC. Thus, when the affinity of the factor for GTP is very high, ppGpp cannot compete for the 30S-bound IF2 and translation can occur. In this study it was shown that tufA mRNA, expressing elongation factor EF-Tu, enhances the affinity of GTP for $30 \mathrm{~S}$ complexes thereby increasing the tolerance for ppGpp and allowing efficient translation. On the contrary, the 

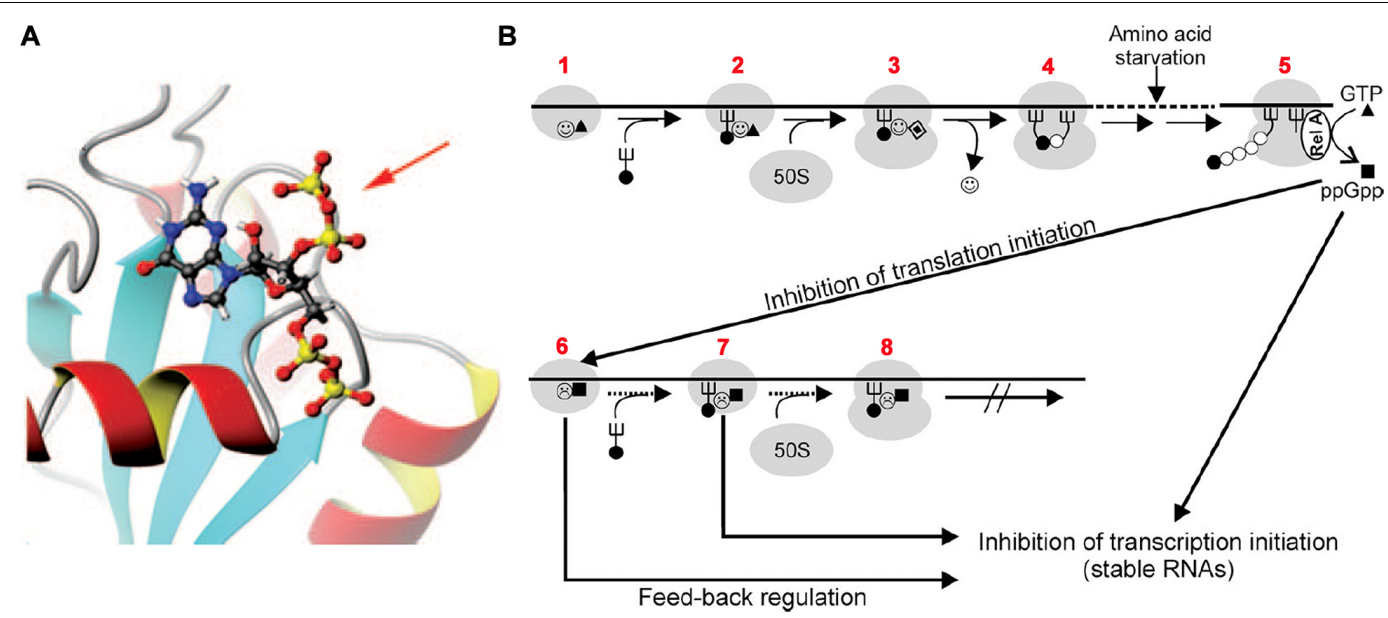

FIGURE 5 | Translation initiation inhibition by ppGpp binding to initiation factor IF2. (A) 3D NMR structure of the G-2 domain of Geobacillus stearothermophilus IF2 complexed with a ppGpp molecule (represented by "balls and sticks"). The $3^{\prime}$ diphosphate protruding out of the IF2 domain is indicated by a red arrow. (B) Scheme of the postulated regulatory circuits involving IF2 and ppGpp upon nutrient starvation. Steps: 1-2 - formation of 30SIC in the presence of IF2-GTP (:) $\mathbf{\Delta}$ ), 2-3association of 50 S subunit and formation of 70SIC and GTP $(\mathbf{\Delta})$ hydrolysis to GDP $(\diamond)$, 3-4 - IF2 (:) dissociation and initiation dipeptide formation. $5-$ Amino acid starvation during elongation triggers RelA-dependent synthesis of ppGpp (ם), which inhibits the translation initiation functions of IF2 (:) such as $30 \mathrm{SIC}$ and initiation dipeptide formation, generating also a feed-back inhibition of stable RNA transcription since IF2, fMet-tRNA, and ppGpp were found to interact with the RNA polymerase and influence its activity at stable RNA promoters (Debenham et al., 1980; Travers et al., 1980), while IF2 (Cole et al., 1987), IF3 (Olsson et al., 1996), and initiation-competent $30 \mathrm{~S}$ subunits (Yamagishi et al., 1987) were shown to be required for feedback repression of stable RNA transcription. Figures taken from Milon et al. (2006). Copyright (2006) National Academy of Sciences.

GTP affinity in complexes containing infA mRNA, expressing initiation factor IF1, was low enough to allow ppGpp to compete with GTP and to block translation initiation (Vinogradova et al., 2020) (Figure 3). The peculiar feature responsible for enhancing GTP affinity and conferring ppGpp tolerance was shown to be the presence of a structured enhancer of translation initiation (SETI) consisting of two consecutive hairpins proximal to the translation initiation region (TIR) of tufA mRNA as well as of several other enterobacterial mRNAs. Furthermore, it was suggested that, whereas the primary sequence of the SETIs is irrelevant, an important role is played by the spatial or conformational constraints which they impose on the initiation complex. Finally, another interesting finding of this study is that IF2 can use the alarmone pppGpp to promote translation initiation, albeit with a reduced efficiency (Figure 3).

\section{Ribosomal Functions Drive the Global Response to Cold Stress}

An abrupt lowering of the temperature below the optimal growth condition is one of the most frequent stressful occurrences experienced by bacterial cells. Regardless of whether the bacteria are thermophilic (Wu and Welker, 1991), mesophilic (Jones et al., 1987; Lottering and Streips, 1995; Phan-Thanh and Gormon, 1995) or psychrophilic (Cloutier et al., 1992; Whyte and Inniss, 2011), a drastic lowering of the ambient temperature causes a "cold shock," which entails extensive reprogramming of the gene expression pattern. Cellular response to cold stress has been extensively studied in the two paradigm Gram negative and Gram positive bacteria, E. coli (Jones and Inouye, 1994; Gualerzi et al., 2003, 2011; Giuliodori, 2016) and B. subtilis
(Graumann et al., 1996, 1997), respectively. In the mesophile E. coli, lowering the temperature from $37^{\circ} \mathrm{C}$ to $<20^{\circ} \mathrm{C}$ causes an immediate block of all macromolecular syntheses, except for a few gene products which are essential for cold adaptation and eventually cell survival (Broeze et al., 1978; Jones et al., 1987; Gualerzi et al., 2003). The precise number of proteins whose expression is increased following cold stress remains somewhat elusive. A set of at least 26 cold-shock genes preferentially and transiently expressed after the stress has been listed for E. coli (Gualerzi et al., 2003), 37 for B. subtilis (Graumann et al., 1996), and 32 for Streptomyces aureofaciens (Mikulik et al., 1999). More recently, a thorough ribosome profiling study identified $116 \mathrm{E}$. coli genes that are upregulated $\geq 2$-fold after cold stress (Zhang et al., 2018). In any event, as seen in the scheme presented in Figure 6, not all cold shock proteins are expressed at the same time; there are cold-induced proteins such as CspA and the three translation initiation factors, which are expressed at an early stage following the stress while others, such as polynucleotide phosphorylase, which are expressed at a later stage. In addition, there are proteins which selectively accumulate in cold-adapted cells. The nature of the cellular receptors responsible for sensing temperature downshift is not clear, but because temperature changes affect a large number of physical and chemical parameters in the cell, it is likely that there might be multiple ways in which thermal stress can be sensed by the cell. In particular, structural modifications of nucleic acids and proteins induced by temperature changes are likely involved in triggering a cascade of events which allow bacteria to adapt to low temperature. Two typical cases in which low temperatureinduced changes of nucleic acid structures result in changes of the gene expression pattern are the virF promoter of Shigella flexneri 
and the transcript of the cspA gene of E. coli. In the case of virF, the gene which controls the pathogenicity cascade of $S$. flexneri, the promoter contains a curved stretch of DNA which represents the target of the transcriptional repressor H-NS. However, the curvature disappears above a threshold temperature so that $\mathrm{H}-\mathrm{NS}$ fails to bind and to block transcription (Falconi et al., 1998). In the case of $\operatorname{csp} A$, the mRNA responds to temperature changes by adopting different functional structures. The mRNA in the coldshock structure is translated more efficiently and is less prone to degradation than the $\operatorname{csp} A$ mRNA in the $37^{\circ} \mathrm{C}$ structure. As a result, immediately after cold stress large amounts of CspA protein are synthesized (Giuliodori et al., 2010).

Most of the regulatory mechanisms involved in the cellular response to cold shock occur at the post-transcriptional level; among these mechanisms the increased half-lives of the transcripts of cold shock genes (Goldenberg et al., 1996) and modifications of the translational apparatus appear to be particularly relevant (Gualerzi et al., 2003). Indeed, there are data suggesting that the ribosome itself might act as a physiological sensor for the thermal stress. In fact, it has been shown that synthesis of stress-related proteins can be induced by the administration of antibiotics which target the ribosome such as chloramphenicol (cold-shock proteins) and kanamycin (heat-shock proteins) (Van Bogelen and Neidhardt, 1990). Aside from this, the ribosomes and the translational apparatus play a fundamental role in the cellular response to cold stress and in the selective translation of cold shock mRNAs while bulk protein synthesis is shut down. In this connection, it was shown that after cold shock, even if present in large amounts in the cell, transcripts of non-cold shock genes are not translated, unlike transcripts of cold shock genes (Brandi et al., 1996).

The selective expression of cold shock proteins while translation of non-cold shock mRNAs is inhibited was termed "translational bias" and its molecular basis was traced back to a modification of the translational apparatus. In particular, translational bias was shown to be due to both cis-acting and trans-acting elements.

Among the cis-acting elements there are the sequences of cspA mRNA, the main cold shock transcript whose structure, as mentioned above, changes at the cold shock temperature acquiring a conformation which makes it better suited for translation in the cold and more resistant to degradation (Giuliodori et al., 2010). The elements present in the cold-shock transcripts which render these mRNAs suitable for translation in the cold were identified analyzing the translational activity of chimeric mRNAs constructed by shuffling regions of $\operatorname{csp} A$ and cspD mRNAs representing the paradigm cold shock and noncold shock transcripts, respectively. From these studies it was concluded that, at least in the case of $\operatorname{csp} A$ mRNA, the coldresponsive elements are located within the first 50 bases of the $5^{\prime} \mathrm{UTR}$ and in the region immediately downstream the initiation triplet (Giuliodori et al., 2019).

Concerning the trans-acting elements, it was shown that upon temperature downshift, transcription and synthesis of the initiation factors IF1 (Giangrossi et al., 2007), IF2 (Brandi et al., 2019a), and IF3 (Giuliodori et al., 2007) are stimulated, whereas maturation of the rRNA and the assembly of ribosomes slow down considerably (Piersimoni et al., 2016). This results in an imbalance of the initiation factor/ribosome ratio which is indeed of great importance for the events leading to cold acclimation of the cell. Whereas the increased level of IF2 does not contribute to translational bias but is important for its participation in the assembly and maturation of ribosomes during cold adaptation (Brandi et al., 2019b), the increased IF3/70S and IF1/70S ratios are at least in part responsible for translational bias. These factors counter the increased tendency of the ribosomal subunits to associate at low temperature, thereby ensuring a sufficient pool of $30 \mathrm{~S}$ subunits for promoting $30 \mathrm{~S}$ initiation complex (30SIC) formation, 50S subunits docking to yield 70SIC and ultimately translation of a select group of cold-shock mRNAs (Giangrossi et al., 2007; Giuliodori et al., 2007) (Figure 7). In particular, IF3 was shown to be the main factor responsible for promoting cold shock mRNA translation and inhibiting non-cold shock mRNAs by targeting the early steps of protein synthesis. This activity of IF3 is strengthened by IF1 (Giuliodori et al., 2004).

Another trans-acting factor which affects translation during cold acclimation is CspA. This protein (70 residues in E. coli), which contains two RNA-binding motifs, RNP1 (K16GFGFI21) and RNP2 (V30FVHF34) on two different $\beta$-strands, binds cooperatively to both single-stranded DNA (ssDNA) and RNA (Jiang et al., 1997). CspA is expressed to very high levels immediately after cold shock so that it was designated as the "major cold shock protein" (Goldstein et al., 1990). However, meticulous studies have later demonstrated that this protein is also present in massive amounts under non-stress conditions, being one of the most abundant proteins during the first rounds of cell division at $37^{\circ} \mathrm{C}$. Subsequently, CspA almost disappears from the cells, being diluted in the cytoplasm of the proliferating cells while new synthesis is limited by the extreme instability acquired by its mRNA (Brandi et al., 1999; Brandi and Pon, 2012). The presence of large amounts of CspA in both cold-stressed cells and in cells growing at $37^{\circ} \mathrm{C}$ indicates that the function of this protein is not restricted to its roles during cold acclimation. Indeed, by virtue of its property of being a single-stranded nucleic acid binding protein, CspA is involved in a number of functions.

Initially, CspA was identified as a factor capable of stimulating transcription of hns (La Teana et al., 1991) and gyrA (Jones et al., 1992) after cold shock, most likely by keeping single-stranded the DNA in the promoter region, thereby favoring promoter clearance (Brandi et al., 1994). Subsequently, it was shown that purified CspA stimulates also translation in vitro (Brandi et al., 1996; Giuliodori et al., 2004), likely by preventing the formation of stable secondary structures in mRNA by virtue of its RNA chaperone activity (Jiang et al., 1997).

It should be mentioned that in addition to CspA, E. coli contains eight CspA paralogs, five of which (CspA, CspB, CspG, CspE, and CspI) are cold-shock inducible (Yamanaka, 1999). These proteins have very similar structural and functional properties so that they may have overlapping functions, but whether or not also these proteins are involved in translation during cold adaptation remains an open question.

Finally, the possibility that cold stress may result in some compositional heterogeneity in the ribosomal population was taken into consideration. However, ribosomes extracted from 


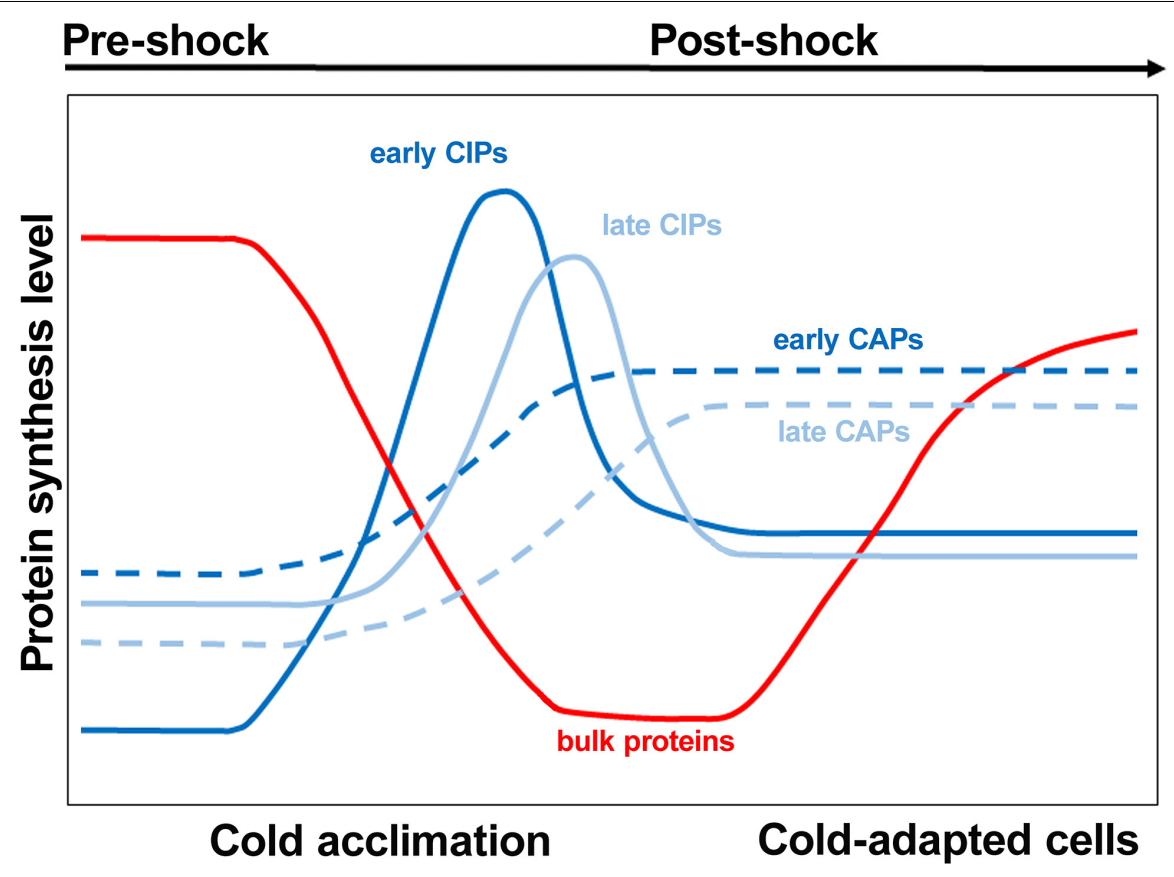

FIGURE 6 | Cold shock induced proteins are expressed at different times after the stress. During the initial stage immediately following cold exposure, the rate of bulk protein synthesis drops while early cold shock proteins such as CspA are synthesized. Subsequently, a group of late cold shock proteins such as polynucleotide phosphorylase starts to accumulate. As the cold acclimation phase nears the end, the levels of cold shock proteins decline while early and late proteins typical of cold-adapted cells are synthesized. Bulk protein synthesis and cell growth resume at the end of the acclimation period. Modified from Weber and Marahiel (2003). Copyright (2003) SAGE publishing.

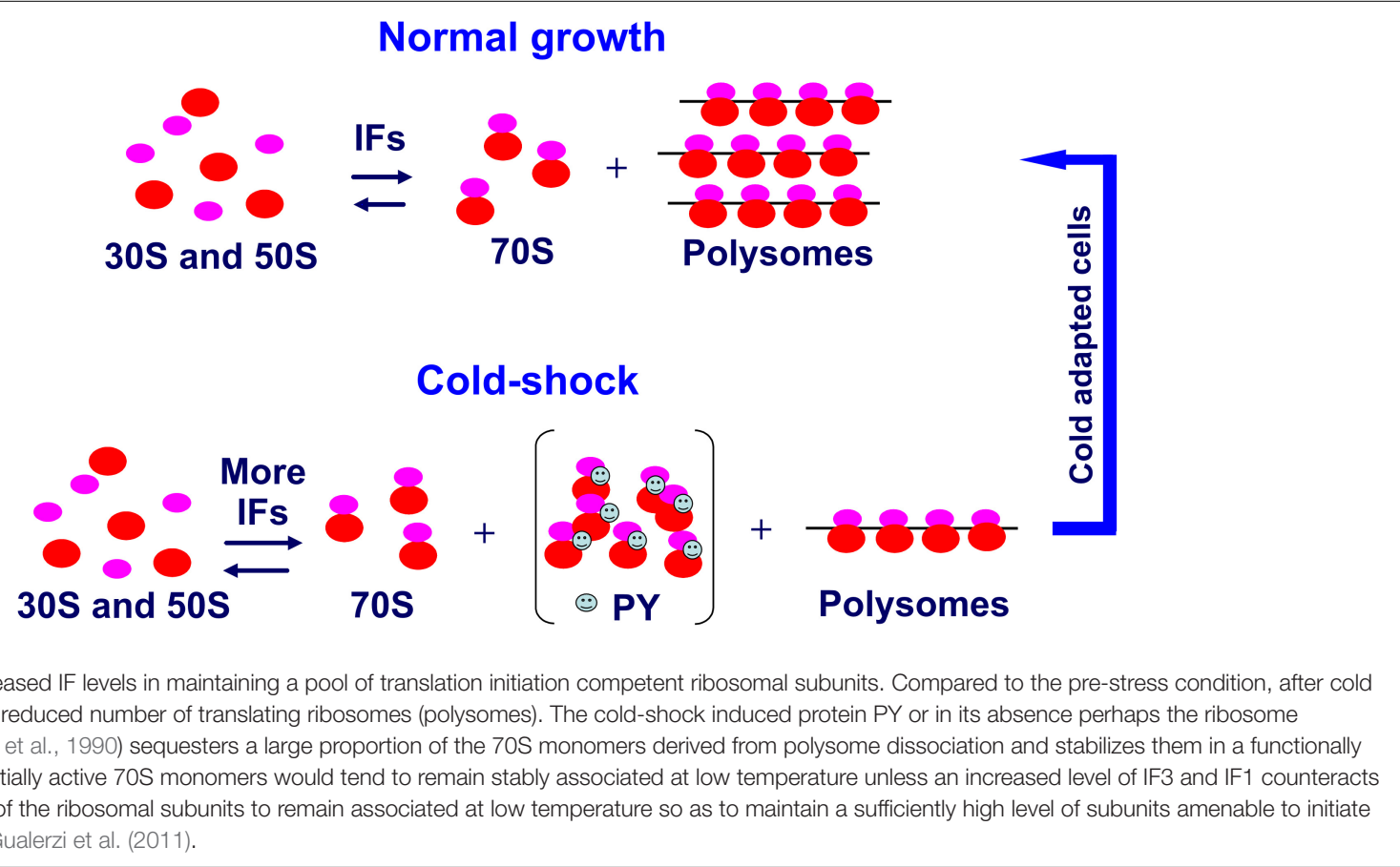

control and cold-shocked cells proved to perform equally well, at least in in vitro translational tests, despite the presence of several post-translational modifications in some ribosomal proteins (Piersimoni, 2010).
Another essential aspect of translational bias is the inhibition of the translation of non-cold-shock mRNAs. It has been calculated that 30 min after cold shock the bulk protein synthesis rate in E. coli drops $\sim 200$-fold as a result of a 50 -fold reduction of 
the translation elongation rate and of a four-fold decrease of the translation initiation rate (Zhang et al., 2018).

The unfavorable mRNA structures acquired by mRNAs at low temperature, which are likely incompatible with translation initiation and elongation, may play a major role in translational silencing. Furthermore, it has been reported that the massive amount of RNA-binding cold shock proteins, which accumulates in stressed cells, overcrowds the mRNAs. In turn, this causes a generalized inhibition of bulk protein synthesis and mRNA degradation by RNaseR, whereas the translation of only a select group of cold-shock transcripts is favored by the RNA-chaperone activity of the Csp proteins (Ermolenko and Makhatadze, 2002; Hofweber et al., 2005; Zhang et al., 2018).

A more selective role in discriminating against translation of non-cold shock mRNAs such as $\operatorname{csp} D$ mRNA is played by IF3. It has been shown in this case that 30SIC formed with this mRNA at cold-shock temperature is endowed with a non-canonical structure and is rejected by IF3 before becoming productive (Gualerzi et al., 2011).

It has been postulated that cold-shock-induced protein PY could be responsible for the repression of bulk translation at the onset of cold adaptation (Agafonov et al., 2001; VilaSanjurjo et al., 2004). In accordance with this hypothesis, analysis of the phenotypes of E. coli PY deletion mutants (Di Pietro et al., 2013) confirmed that PY diminishes bulk translation, reduces translation of some mRNAs, non-cold-shock mRNAs in particular, and influences the timing of cold-shock induction of some proteins. In addition, the data indicated that, although PY cannot destabilize an fMet-tRNA correctly positioned in the 70SIC, its main target at low temperature is translation initiation rather than elongation as previously suggested. However, the extent of translation inhibition by PY was rather modest and recovery from cold stress and inhibition of bulk protein synthesis following cold stress occurred also in the absence of PY. Given the vital importance of blocking bulk translation upon cold shock, it is likely that in the absence of PY the cell may resort to some back up mechanism to reduce translational activity, possibly by overcrowding the mRNAs with large amounts of cold shock-induced RNA-binding proteins. In this connection, PY was shown to reduce the number of ribosomal subunits able to participate in 70SIC formation by sequestering $30 \mathrm{~S}$ and $50 \mathrm{~S}$ subunits and stimulating their association to form idle $70 \mathrm{~S}$ monomers (Figure 7).

Among the proteins whose expression is increased after cold stress are well known DNA binding proteins such as RecA, GyrA/GyrB (Jones et al., 1992), H-NS (La Teana et al., 1991), and HU $\beta$ (Giangrossi et al., 2002). It is known that temperature changes affect the degree of DNA superhelicity and the compaction of the nucleoid and it takes several hours after cold stress before the DNA superhelicity reaches an equilibrium (Goldstein and Drlica, 1984), likely corresponding to the time required for the cold-shock-induced gyrase synthesis. Thus, the gyrase (GyrA/GyrB) and HU, which introduce negative supercoiling (Drlica, 1992; Dorman, 1996; Tse-Dinh et al., 1997), and H-NS, which constrains the DNA superhelicity (Dorman, 1996; Atlung and Ingmer, 1997) could play an important role in the structural rearrangements of the nucleoid which occur upon temperature downshift.

However, it is possible to envisage an additional, perhaps more elusive role in mRNA translation for the cold-induced nucleoidassociated proteins $\mathrm{HU}$ and $\mathrm{H}-\mathrm{NS}$. Indeed, both HU and H-NS have been shown to affect protein synthesis in particular cases.

Translation of malT mRNA is stimulated by H-NS which facilitates the assembly of a 30 S initiation complex (30SIC) on this mRNA whose $5^{\prime}$ UTR possesses some particular properties consisting in a suboptimal ribosome-binding sequence and in the presence of an AU-rich region at -35 to -40 (Figure 8). In this connection it should be remarked that $\mathrm{AU}$ rich enhancers stimulate translation in co-operation with the SD sequences and that shorter SD sequences are preferred at lower temperatures
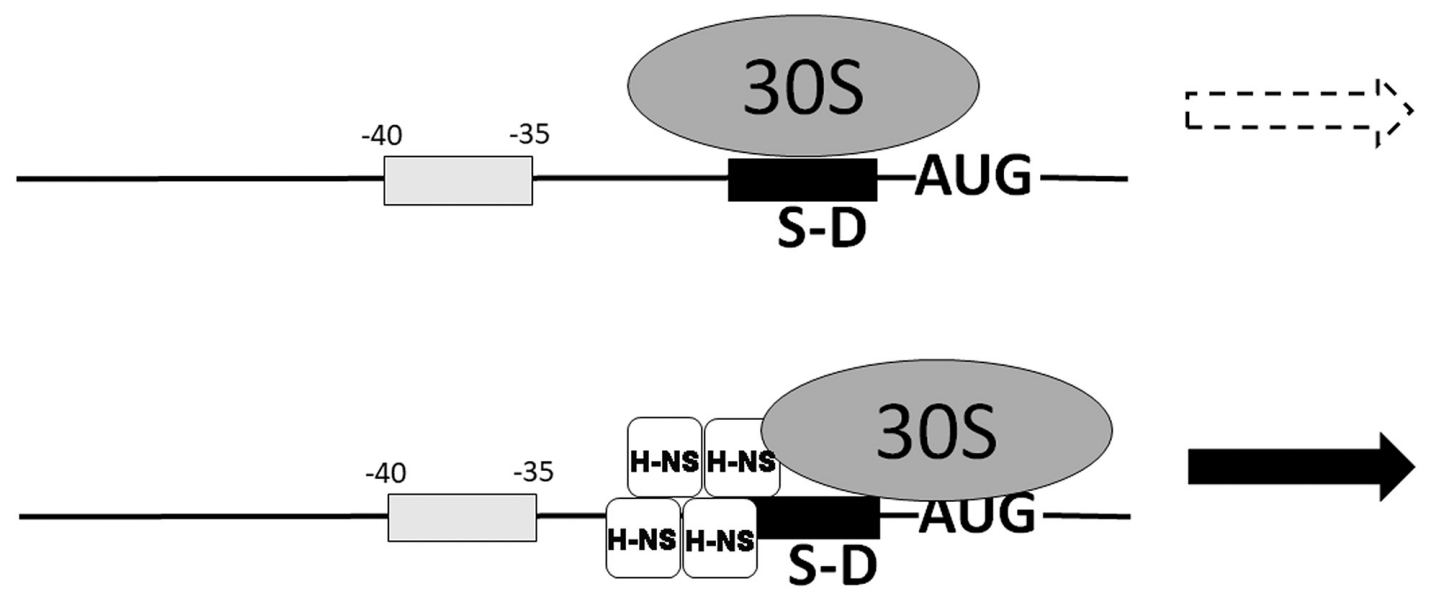

FIGURE 8 | Nucleoid-associated transcriptional inhibitor H-NS can promote translation of some mRNAs. The translation of some mRNAs characterized by a weak SD sequence and an A, T-rich box between -35 and -40 is stimulated by nucleoid-associated protein $\mathrm{H}$-NS which places the $30 \mathrm{~S}$ ribosomal subunit in a new position, promotes 30SIC formation and stimulates translation (Park et al., 2010). H-NS is bound to the mRNA near the 30S ribosomal subunit and represented as a tetramer which is the active form of this protein, according to our studies (Spurio et al., 1997; Stella et al., 2005). Modified from Park et al. (2010). 
(Vimberg et al., 2007). It seems noteworthy that H-NS stimulates also the translation of other mRNAs whose $5^{\prime}$ UTRs have similar characteristics (Park et al., 2010). However, among the large number of genes whose expression is stimulated by cold shock (Zhang et al., 2018) the $5^{\prime}$ UTR of only four ORFS ( $y m g A$, yehU, $y r h B$, and $y l b H)$ have characteristics similar to typical H-NS targets.

Like H-NS, also HU was shown to influence the level of translation, at least in one particular case. Upon binding with high specificity to the rpoS mRNA, HU was found to stimulate the synthesis of the stress $\sigma^{S}$ factor of RNA polymerase (Balandina et al., 2001). It seems interesting in this connection that $\mathrm{HU}$ and $\mathrm{H}-\mathrm{NS}$ have antagonistic effects on the expression of $\sigma^{S}$. In fact, HU binds DsrA, a small non-coding RNA that regulates transcription by repressing $\mathrm{H}-\mathrm{NS}$ and stimulates translation by increasing expression of rpoS.

These results are in accordance with earlier findings that during the acclimation phase of cold shock the protein expression pattern of the organism drastically changes.

\section{CONCLUSION AND PERSPECTIVES}

The translational apparatus plays an essential role in the production of vital cell constituents like proteins. In addition to this primary function, the translational apparatus plays an active role in reprogramming gene expression and proteome composition, as illustrated by the mechanisms by which bacteria cope with the three stress situations outlined above. Although considerable amount of work has been devoted to clarify the events occurring in the cells following zinc and nutrient shortage and cold stress, several aspects of cellular responses to these stresses deserve further investigation. The signals which promote the replacement of the $\mathrm{Zn}$-containing ribosomal proteins by their paralogs and the mechanisms by which this replacement takes place and the subsequent steps leading to an increase of free zinc availability in the cytoplasm should be clarified. The mechanism by which translation of a select group of mRNAs is favored by ppGpp remains unclear. In particular, it would be important to understand what is responsible for the modulation

\section{REFERENCES}

Agafonov, D. E., Kolb, V. A., and Spirin, A. S. (2001). Ribosome associated protein that inhibits translation at the aminoacyl-tRNA binding stage. EMBO Rep. 2, 399-402. doi: 10.1093/embo-reports/kve091

Akanuma, G., Nanamiya, H., Natori, Y., Nomura, N., and Kawamura, F. (2006). Liberation of zinc-containing L31 (RpmE) from ribosomes by its paralogous gene product, YtiA, in Bacillus subtilis. J. Bacteriol. 188, 2715-2720. doi: 10. 1128/jb.188.7.2715-2720.2006

Andreini, C., Bertini, I., Cavallaro, G., Holliday, G. L., and Thornton, J. M. (2008). Metal ions in biological catalysis: from enzyme databases to general principles. J. Biol. Inorg. Chem. 13, 1205-1218. doi: 10.1007/s00775-008-04045

Arai, T., Ishiguro, K., Kimura, S., Sakaguchi, Y., Suzuki, T., and Suzuki, T. (2015). Single methylation of $23 \mathrm{~S}$ rRNA triggers late steps of $50 \mathrm{~S}$ ribosomal subunit assembly. Proc. Natl. Acad. Sci. U.S.A. 112, E4707-E4716.

Arenz, S., Abdelshahid, M., Sohmen, D., Payoe, R., Starosta, A. L., Berninghausen, O., et al. (2016). The stringent factor RelA adopts an open conformation on of IF2 affinity for GTP and ppGpp. In light of the recent findings that several small non-coding RNAs (sRNAs) may affect translation in cis or in trans, thereby providing effective responses to different types of stress (e.g., metabolite, nutrient, oxidative, envelope, iron, acidic, anaerobic, and heat stresses) (Citartan et al., 2016; Jagodnik et al., 2016), it would be important to investigate if sRNAs may also play a role in cold shocked cells. Concerning the cold shock-induced modifications of the translational apparatus, it should be determined if cold stress alters the RNA post-transcriptional modification patterns and if the post-translational modifications of the ribosomal proteins observed in cold shocked cells (Piersimoni, 2010) have any functional implication. Also the role, if any, played by cold-shock RNA binding proteins other than CspA in inhibiting bulk protein synthesis and favoring translation of cold-shock transcripts should be investigated. Finally, a thorough characterization of cold-adapted cells which grow and divide at suboptimal temperatures is still lacking.

\section{AUTHOR CONTRIBUTIONS}

HC-G and CG contributed to writing the MS. Both authors contributed to the article and approved the submitted version.

\section{FUNDING}

Funds for open access publication fees from: Scientific and Technological Developing Scheme of Ji Lin Province (China), and 20190701054GH China Scholarship Council: 201705965013 Department of Education of Jilin Province (China), JJKH20200321KJ.

\section{ACKNOWLEDGMENTS}

The critical discussions of Cynthia L. Pon and Anna Maria Giuliodori as well as the help of Attilio Fabbretti in the preparation of the figures are gratefully acknowledged.

the ribosome to stimulate ppGpp synthesis. Nucleic Acids Res. 44, 6471-6481. doi: 10.1093/nar/gkw470

Atkinson, G. C., Tenson, T., and Hauryliuk, V. (2011). The RelA/SpoT homolog (RSH) superfamily: distribution and functional evolution of ppGpp synthetases and hydrolases across the tree of life. PLoS One 6:e23479. doi: 10.1371/journal. pone.0023479

Atlung, T., and Ingmer, H. (1997). H-NS: a modulator of environmentally regulated gene expression. Mol. Microbiol. 24, 7-17. doi: 10.1046/j.1365-2958. 1997.3151679.x

Baba, T., Ara, T., Hasegawa, M., Takai, Y., Okumura, Y., Baba, M., et al. (2006). Construction of Escherichia coli K-12 in-frame, single-gene knockout mutants: the Keio collection. Mol. Syst. Biol. 2:2006.0008.

Balandina, A., Claret, L., Hengge-Aronis, R., and Rouviere-Yaniv, J. (2001). The Escherichia coli histone-like protein HU regulates rpoS translation. Mol. Microbiol. 39, 1069-1079. doi: 10.1046/j.1365-2958.2001.02305.x

Becker, K. W., and Skaar, E. P. (2014). Metal limitation and toxicity at the interface between host and pathogen. FEMS Microbiol. Rev. 38, 1235-1249. doi: 10.1111/ 1574-6976.12087 
Brandi, A., Giangrossi, M., Paoloni, S., Spurio, R., Pon, C. L., and Gualerzi, C. O. (2019a). Transcriptional and post-transcriptional events trigger de novo infB expression in cold stressed Escherichia coli cells. Nucleic Acids Res. 47, 4638-4651. doi: 10.1093/nar/gkz187

Brandi, A., Piersimoni, L., Feto, A. N., Spurio, R., Alix, J. H., Schmidt, F., et al. (2019b). Translation initiation factor IF2 contributes to ribosome assembly and maturation during cold adaptation. Nucleic Acids Res. 47, 4652-4662. doi: 10.1093/nar/gkz188

Brandi, A., Pietroni, P., Gualerzi, C. O., and Pon, C. L. (1996). Post-transcriptional regulation of CspA expression in Escherichia coli. Mol. Microbiol. 19, 231-240. doi: 10.1046/j.1365-2958.1996.362897.x

Brandi, A., and Pon, C. L. (2012). Expression of Escherichia coli cspA during early exponential growth at $37^{\circ} \mathrm{C}$. Gene $492,382-388$. doi: $10.1016 /$ j.gene. 2011 . 10.047

Brandi, A., Pon, C. L., and Gualerzi, C. O. (1994). Interaction of the main cold shock protein CS 7.4 (CspA) of Escherichia coli with the promoter region of hns. Biochimie 76, 1090-1098. doi: 10.1016/0300-9084(94)90035-3

Brandi, A., Spurio, R., Gualerzi, C. O., and Pon, C. L. (1999). Massive presence of the Escherichia coli 'major cold-shock protein' CspA under non-stress conditions. EMBO J. 18, 1653-1659. doi: 10.1093/emboj/18.6.1653

Broeze, R. J., Solomon, C., and Pope, D. H. (1978). Effects of low temperature on in vivo and in vitro protein synthesis in Escherichia coli and Pseudomonas fluorescens. J. Bacteriol. 134, 861-874. doi: 10.1128/jb.134.3.861-874.1978

Brown, A., Fernández, I. S., Gordiyenko, Y., and Ramakrishnan, V. (2016). Ribosome-dependent activation of stringent control. Nature 534, 277-280. doi: 10.1038 /nature 17675

Carlson, M. A., Haddad, B. H., Weis, A. J., Blackwood, C. S., Shelton, C. D., Wuerth, M. E., et al. (2017). Ribosomal protein L7/L12 is required for GTPase translation factors EF-G, RF3, and IF2 to bind in their GTP state to 70 S ribosomes. FEBS J. 284, 1631-1643. doi: 10.1111/febs.14067

Cerasi, M., Ammendola, S., and Battistoni, A. (2013). Competition for zinc binding in the host-pathogen interaction. Front. Cell. Infect. Microbiol. 3:108. doi: 10. 3389/fcimb.2013.00108

Chatterji, D., Fujita, N., and Ishihama, A. (1998). The mediator for stringent control, ppGpp, binds to the beta-subunit of Escherichia coli RNA polymerase. Genes Cells 3, 279-287. doi: 10.1046/j.1365-2443.1998.00190.x

Chatterji, D., and Ojha, A. K. (2001). Revisiting the stringent response, ppGpp and starvation signaling. Curr. Opin. Microbiol. 4, 160-165. doi: 10.1016/s13695274(00)00182-x

Chen, S. S., and Williamson, J. R. (2013). Characterization of the ribosome biogenesis landscape in $\mathrm{E}$. coli using quantitative mass spectrometry. J. Mol. Biol. 425, 767-779. doi: 10.1016/j.jmb.2012.11.040

Citartan, M., Raabe, C. A., Hoe, C. H., Rozhdestvensky, T. S., and Tang, T. H. (2016). "Bacterial sRNAs: regulation in stress," in Stress and Environmental Regulation of Gene Expression and Adaptation in Bacteria, ed. F. J. de Bruijn (Hoboken, NJ: John Wiley \& Sons, Inc).

Cloutier, J., Prevost, D., Nadeau, P., and Antoun, H. (1992). Heat and cold shock protein synthesis in arctic and temperate strains of rhizobia. Appl. Environ. Microbiol. 58, 2846-2853. doi: 10.1128/aem.58.9.2846-2853.1992

Cole, J. R., Olsson, C. L., Hershey, J. W., Grunberg-Manago, M., and Nomura, M. (1987). Feedback regulation of rRNA synthesis in Escherichia coli. Requirement for initiation factor IF2. J. Mol. Biol. 198, 383-392. doi: 10.1016/0022-2836(87) 90288-9

Debenham, P. G., Pongs, O., and Travers, A. A. (1980). Formylmethionyl-tRNA alters RNA polymerase specificity. Proc. Natl. Acad. Sci. U.S.A. 77, 870-874. doi: 10.1073/pnas.77.2.870

Di Pietro, F., Brandi, A., Dzeladini, N., Fabbretti, A., Carzaniga, T., Piersimoni, L., et al. (2013). Role of the ribosome-associated protein PY in the cold shock response of Escherichia coli. Microbiologyopen 2, 293-307. doi: 10.1002/ mbo3.68

Diaconu, M., Kothe, U., Schlünzen, F., Fischer, N., Harms, J. M., Tonevitsky, A. G., et al. (2005). Structural basis for the function of the ribosomal L7/12 stalk in factor binding and GTPase activation. Cell 121, 991-1004. doi: 10.1016/j.cell. 2005.04.015

Diez, S., Ryu, J., Caban, K., Gonzalez, R. L. Jr., and Dworkin, J. (2020). The alarmones (p)ppGpp directly regulate translation initiation during entry into quiescence. Proc. Natl. Acad. Sci. U.S.A. 117, 15565-15572.
Dorman, C. J. (1996). Flexible response: DNA supercoiling, transcription and bacterial adaptation to environmental stress. Trends Microbiol. 4, 214-216. doi: 10.1016/0966-842x(96)30015-2

Drlica, K. (1992). Control of bacterial DNA supercoiling. Mol. Microbiol. 6, 425 433. doi: 10.1111/j.1365-2958.1992.tb01486.x

Ermolenko, D. N., and Makhatadze, G. I. (2002). Bacterial cold-shock proteins. Cell. Mol. Life Sci. 59, 1902-1913. doi: 10.1007/pl00012513

Fabbretti, A., Brandi, L., Milón, P., Spurio, R., Pon, C. L., and Gualerzi, C. O. (2012). Translation initiation without IF2-dependent GTP hydrolysis. Nucleic Acids Res. 40, 7946-7955. doi: 10.1093/nar/gks569

Falconi, M., Colonna, B., Prosseda, G., Micheli, G., and Gualerzi, C. O. (1998). Thermoregulation of Shigella and Escherichia coli EIEC pathogenicity. A temperature-dependent structural transition of DNA modulates accessibility of virF promoter to transcriptional repressor H-NS. EMBO J. 17, 7033-7043. doi: $10.1093 / \mathrm{emboj} / 17.23 .7033$

Fernández-Coll, L., and Cashel, M. (2020). Possible roles for basal levels of (p)ppGpp: growth efficiency Vs. surviving stress. Front. Microbiol. 11:592718. doi: $10.3389 /$ fmicb. 2020.592718

Fischer, N., Neumann, P., Konevega, A. L., Bock, L. V., Ficner, R., Rodnina, M. V., et al. (2015). Structure of the E. coli ribosome-EF-Tu complex at $<3$ $\AA$ resolution by Cs-corrected cryo-EM. Nature 520, 567-570. doi: 10.1038/ nature 14275

Gabriel, S. E., and Helmann, J. D. (2009). Contributions of Zur-controlled ribosomal proteins to growth under zinc starvation conditions. J. Bacteriol. 191, 6116-6122. doi: 10.1128/jb.00802-09

Giangrossi, M., Brandi, A., Giuliodori, A. M., Gualerzi, C. O., and Pon, C. L. (2007). Cold-shock-induced de novo transcription and translation of infA and role of IF1 during cold adaptation. Mol. Microbiol. 64, 807-821. doi: 10.1111/j.13652958.2007.05699.x

Giangrossi, M., Giuliodori, A. M., Gualerzi, C. O., and Pon, C. L. (2002). Selective expression of the $\beta$-subunit of nucleoid-associated protein HU during cold shock in Escherichia coli. Mol. Microbiol. 44, 205-216. doi: 10.1046/j.1365-2958. 2002.02868.x

Gilston, B. A., Wang, S., Marcus, M. D., Canalizo-Hernández, M. A., Swindell, E. P., et al. (2014). Structural and mechanistic basis of zinc regulation across the E. coli Zur regulon. PLoS Biol. 12:e1001987. doi: 10.1371/journal.pbio.10 01987

Giuliodori, A. M. (2016). "Cold shock response in Escherichia coli a model system to study posttranscriptional regulation," in Stress and Environmental Regulation of Gene Expression and Adaptation in Bacteria, ed. F. J. de Bruijn (Hoboken, NJ: John Wiley \& Sons, Inc).

Giuliodori, A. M., Brandi, A., Gualerzi, C. O., and Pon, C. L. (2004). Preferential translation of cold-shock mRNAs during cold adaptation. RNA 10, 265-276. doi: 10.1261/rna.5164904

Giuliodori, A. M., Di Pietro, F., Marzi, S., Masquida, B., Wagner, R., Romby, P., et al. (2010). The cspA mRNA is a thermosensor that modulates translation of the cold-shock protein CspA. Mol. Cell 37, 21-33. doi: 10.1016/j.molcel.2009. 11.033

Giuliodori, A. M., Fabbretti, A., and Gualerzi, C. O. (2019). Cold-responsive regions of paradigm cold-shock and non-cold-shock mRNAs responsible for cold shock translational bias. Int. J. Mol. Sci. 20:E457.

Giuliodori, A. M., Giangrossi, M., Brandi, A., Gualerzi, C. O., and Pon, C. L. (2007). Cold-stress-induced de novo expression of infC and role of IF3 in cold-shock translational bias. RNA 13, 1355-1365. doi: 10.1261/rna.455607

Goldenberg, D., Azar, I., and Oppenheim, A. B. (1996). Differential mRNA stability of the cspA gene in the cold-shock response of Escherichia coli. Mol. Microbiol. 19, 241-248. doi: 10.1046/j.1365-2958.1996.363898.x

Goldstein, E., and Drlica, K. (1984). Regulation of bacterial DNA supercoiling: plasmid linking numbers vary with growth temperature. Proc. Natl. Acad. Sci. U.S.A. 81, 4046-4050. doi: 10.1073/pnas.81.13.4046

Goldstein, J., Pollitt, N. S., and Inouye, M. (1990). Major cold shock protein of Escherichia coli. Proc. Natl. Acad. Sci. U.S.A. 87, 283-287. doi: 10.1073/pnas.87. 1.283

Graham, A. I., Hunt, S., Stokes, S. L., Bramall, N., Bunch, J., et al. (2009). Severe zinc depletion of Escherichia coli: roles for high affinity zinc binding by ZinT, zinc transport and zinc-independent proteins. J. Biol. Chem. 284, 18377-18389. doi: 10.1074/jbc.m109.001503 
Graumann, P., Schroeder, K., Schmid, R., and Marahiel, M. A. (1996). Cold shock stress-induced proteins in Bacillus subtilis. J. Bacteriol. 178, 4611-4619. doi: 10.1128/jb.178.15.4611-4619.1996

Graumann, P., Wendrich, T. M., Weber, M. H. W., Schröder, K., and Marahiel, M. A. (1997). A family of cold shock proteins in Bacillus subtilis is essential for cellular growth and for efficient protein synthesis at optimal and low temperatures. Mol. Microbiol. 25, 741-756. doi: 10.1046/j.1365-2958.1997. 5121878.x

Green, J. M., Nichols, B. P., and Matthews, R. G. (1996). "Folate metabolism, reduction and polyglutamylation," in Escherichia coli and Salmonella typhimurium, 2nd Edn, ed. F. C. Neidhardt (Washington, DC: ASM Press), 665-673.

Gropp, M., Strausz, Y., Gross, M., and Glaser, G. (2001). Regulation of Escherichia coli RelA requires oligomerization of the C-terminal domain. J. Bacteriol. 183, 570-579. doi: 10.1128/jb.183.2.570-579.2001

Gualerzi, C. O., Giuliodori, A. M., Brandi, A., Di Pietro, F., Piersimoni, L., Fabbretti, A., et al. (2011). "Translation initiation at the root of the coldshock translational bias," in Ribosomes-Structure, Function, and Dynamics, eds M. V. Rodnina, W. Wintermeyer, and R. Green (Wien: Springer), 143-154. doi: 10.1007/978-3-7091-0215-2_12

Gualerzi, C. O., Giuliodori, A. M., and Pon, C. L. (2003). Transcriptional and post-transcriptional control of cold-shock genes. J. Mol. Biol. 331, 527-539. doi: 10.1016/s0022-2836(03)00732-0

Gualerzi, C. O., and Pon, C. L. (2015). Initiation of mRNA translation in bacteria: structural and dynamic aspects. Cell. Mol. Life Sci. 72, 4341-4367. doi: 10.1007/ s00018-015-2010-3

Gualerzi, C. O., Severini, M., Spurio, R., La Teana, A., and Pon, C. L. (1991). Molecular dissection of translation initiation factor IF2. Evidence for two structural and functional domains. J. Biol. Chem. 266, 16356-16362.

Guenneugues, M., Caserta, E., Brandi, L., Spurio, R., Meunier, S., Pon, C. L., et al. (2000). Mapping the fMet-tRNAfMet binding site of initiation factor IF2. EMBO J. 19, 5233-5240. doi: 10.1093/emboj/19.19.5233

Hantke, K. (2005). Bacterial zinc uptake and regulators. Curr. Opin. Microbiol. 8, 196-202. doi: 10.1016/j.mib.2005.02.001

Hauryliuk, V., Gemma, C., Atkinson, G. C., Murakami, K. S., Tenson, T., and Gerdes, K. (2015). Recent functional insights into the role of (p)ppGpp in bacterial physiology. Nat. Rev. Microbiol. 13, 298-309. doi: 10.1038/ nrmicro3448

Hemm, M. R., Paul, B. J., Miranda-Ríos, J., Zhang, A., Soltanzad, N., and Storz, G. (2010). Small stress response proteins in Escherichia coli: proteins missed by classical proteomic studies. J. Bacteriol. 192, 46-58. doi: 10.1128/jb.00872-09

Hensley, M. P., Gunasekera, T. S., Easton, J. A., Sigdel, T. K., Sugarbaker, S. A., et al. (2012). Characterization of $\mathrm{Zn}$ (II)-responsive ribosomal proteins $\mathrm{YkgM}$ and L31 in E. coli. J. Inorg. Biochem. 111, 164-172. doi: 10.1016/j.jinorgbio. 2011.11.022

Hofweber, R., Horn, G., Langmann, T., Balbach, J., Kremer, W., Gerd Schmitz, G., et al. (2005). The influence of cold shock proteins on transcription and translation studied in cell-free model systems. FEBS J. 272, 4691-4702. doi: 10.1111/j.1742-4658.2005.04885.x

Jagodnik, J., Thieffry, D., and Guillier, M. (2016). "Bacterial small RNAs in mixed regulatory circuits," in Stress and Environmental Regulation of Gene Expression and Adaptation in Bacteria, ed. F. J. de Bruijn (Hoboken, NJ: John Wiley \& Sons, Inc).

Jiang, M., Sullivan, S. M., Patrice, K., Wout, P. K., and Maddock, J. R. (2007). G-protein control of the ribosome-associated stress response protein SpoT. J. Bacteriol. 189, 6140-6147. doi: 10.1128/jb.00315-07

Jiang, W., Hou, Y., and Inouye, M. (1997). CspA, the major cold-shock protein of Escherichia coli, is an RNA chaperone. J. Biol. Chem. 272, 196-202. doi: 10.1074/jbc.272.1.196

Jones, P. G., and Inouye, M. (1994). The cold shock response- a hot topic. Mol. Microbiol. 11, 811-818. doi: 10.1111/j.1365-2958.1994.tb00359.x

Jones, P. G., Krah, R., Tafuri, S. R., and Wolffe, A. P. (1992). DNA gyrase, CS7.4, and the cold shock response in Escherichia coli. J. Bacteriol. 174, 5798-5802. doi: 10.1128/jb.174.18.5798-5802.1992

Jones, P. G., Van Bogelen, R. A., and Neidhardt, F. C. (1987). Induction of proteins in response to low temperatures in Escherichia coli. J. Bacteriol. 169, 2092-2095. doi: 10.1128/jb.169.5.2092-2095.1987
Katayama, A., Tsujii, A., Wada, A., Nishino, T., and Ishihama, A. (2002). Systematic search for zinc-binding proteins in Esherichia coli. Eur. J. Biochem. 269, 24032413. doi: 10.1046/j.1432-1033.2002.02900.x

Kehl-Fie, T. E., and Skaar, E. P. (2010). Nutritional immunity beyond iron: a role for manganese and zinc. Curr. Opin. Chem. Biol. 14, 218-224. doi: 10.1016/j. cbpa.2009.11.008

Kim, Y., Cunningham, M. A., Mire, J., Tesar, C., Sacchettini, J., and Joachimiak, A. (2013). NDM-1, the ultimate promiscuous enzyme: substrate recognition and catalytic mechanism. FASEB J. 27, 1917-1927. doi: 10.1096/fj.12-224014

Kim, Y., Tesar, C., Mire, J., Jedrzejczak, R., Binkowski, A., Babnigg, G., et al. (2011). Structure of apo- and monometalated forms of NDM-1-a highly potent carbapenem-hydrolyzing metallo- $\beta$-lactamase. PLoS One 6:e24621. doi: 10. 1371/journal.pone.0024621

Koch, M., Flur, S., Kreutz, C., Ennifar, E., Micura, R., and Polacek, N. (2015). Role of a ribosomal RNA phosphate oxygen during the EF-G-triggered GTP hydrolysis. Proc. Natl. Acad. Sci. U.S.A. 112, E2561-E2568.

Korostrelev, A. A. (2011). Structural aspects of translation termination on the ribosome. RNA 17, 1409-1421. doi: 10.1261/rna.2733411

Kriel, A., Bittner, A. N., Kim, S. H., Liu, K., Tehranchi, A. K., et al. (2012). Direct regulation of GTP homeostasis by (p)ppGpp: a critical component of viability and stress resistance. Mol. Cell 48, 231-241. doi: 10.1016/j.molcel.2012.08.009

La Teana, A., Brandi, A., Falconi, M., Spurio, R., Pon, C. L., and Gualerzi, C. O. (1991). Identification of a cold shock transcriptional enhancer of the Escherichia coli gene encoding nucleoid protein H-NS. Proc. Natl. Acad. Sci. U.S.A. 88, 10907-10911. doi: 10.1073/pnas.88.23.10907

La Teana, A., Gualerzi, C. O., and Dahlberg, A. E. (2001). Initiation factor 2 binds to the $\alpha$-sarcin loop and helix 89 of Escherichia coli 23 S ribosomal RNA. RNA 7, 1173-1179. doi: 10.1017/s1355838201010366

Lottering, E. A., and Streips, U. N. (1995). Induction of cold shock proteins in Bacillus subtilis. Curr. Microbiol. 30, 193-199. doi: 10.1007/bf00293633

Loveland, A. B., Bah, E., Madireddy, R., Zhang, Y., Brilot, A. F., Grigorieff, N., et al. (2016). Ribosome-RelA structures reveal the mechanism of stringent response activation. eLife 5:e17029.

Maciąg-Dorszyńska, M., Szalewska-Pałasz, A., and Węgrzyn, G. (2013). Different effects of ppGpp on Escherichia coli DNA replication in vivo and in vitro. FEBS Open Bio 3, 161-164.

Maeder, C., and Draper, D. E. (2005). A small protein unique to bacteria organizes rRNA tertiary structure over an extensive region of the $50 \mathrm{~S}$ ribosomal subunit. J. Mol. Biol. 354, 436-446. doi: 10.1016/j.jmb.2005.09.072

Magnusson, L. U., Farewell, A., and Nystrom, T. (2005). ppGpp: a global regulator in Escherichia coli. Trends Microbiol. 13, 236-242. doi: 10.1016/j.tim.2005. 03.008

Makarova, K. S., Ponomarev, V. A., and Koonin, E. V. (2001). Two C or not two $\mathrm{C}$ : recurrent disruption of $\mathrm{Zn}$-ribbons, gene duplication, lineage-specific gene loss, and horizontal gene transfer in evolution of bacterial ribosomal proteins. Genome Biol. 2:RESEARCH 0033.

Mangroo, D., Wu, X. Q., and RajBhandary, U. L. (1995). Escherichia coli initiator tRNA: structure-function relationships and interactions with the translational machinery. Biochem. Cell Biol. 73, 1023-1031. doi: 10.1139/o95-109

Mayer, C., Stortchevoi, A., Köhrer, C., Varshney, U., and RajBhandary, U. L. (2001). Initiator tRNA and its role in initiation of protein synthesis. Cold Spring Harb. Symp. Quant. 66, 195-206. doi: 10.1101/sqb.2001.66.195

McCarthy, J. E. G., and Gualerzi, C. (1990). Translational control of prokaryotic gene expression. Trends Genet. 6, 78-85. doi: 10.1016/0168-9525(90)90098-q

Mechold, U., Potrykus, K., Murphy, H., Murakami, K. S., and Cashel, M. (2013). Differential regulation by ppGpp versus pppGpp in Escherichia coli. Nucleic Acids Res. 41, 6175-6189. doi: 10.1093/nar/gkt302

Mechulam, Y., Schmitt, E., Maveyraud, L., Zelwer, C., Nureki, O., Yokoyama, S., et al. (1999). Crystal structure of E. coli methionyl-tRNA synthetase highlights: species-specific features. J. Mol. Biol. 294, 1287-1297. doi: 10.1006/jmbi.1999. 3339

Mikulik, K., Khanh-Hoang, Q., Halada, P., Bezouskova, S., Benada, O., and Behal, V. (1999). Expression of the Csp protein family upon cold shock and production of tetracycline in Streptomyces aureofaciens. Biochem. Biophys. Res. Commun. 265, 305-310. doi: 10.1006/bbrc.1999.1673

Milon, P., Carotti, M., Konevega, A. L., Wintermeyer, W., Rodnina, M. V., et al. (2010). The ribosome-bound initiation factor 2 recruits initiator tRNA to 
the 30 S initiation complex. EMBO Rep. 11, 312-316. doi: $10.1038 /$ embor. 2010.12

Milon, P., Tischenko, E., Tomšic, J., Caserta, E., Folkers, G., La Teana, A., et al. (2006). The nucleotide-binding site of bacterial translation initiation factor 2 (IF2) as a metabolic sensor. Proc. Natl. Acad. Sci. U.S.A. 103, 13962-13967. doi: 10.1073/pnas.0606384103

Mitkevich, V. A., Ermakov, A., Kulikova, A. A., Tankov, S., Soosaar, A., Tenson, T., et al. (2010). Thermodynamic characterization of ppGpp binding to EFG or IF2 and of initiator tRNA binding to free IF2 in the presence of GDP, GTP, or ppGpp. J. Mol. Biol. 402, 838-846. doi: 10.1016/j.jmb.2010.08.01 6

Moore, C. M., and Helmann, J. D. (2005). Metal ion homeostasis in Bacillus subtilis. Curr. Opin. Microbiol. 8, 188-195. doi: 10.1016/j.mib.2005.02.007

Nanamiya, H., Akanuma, G., Natori, Y., Murayama, R., Kosono, S., Kudo, T., et al. (2004). Zinc is a key factor in controlling alternation of two types of L31 protein in the Bacillus subtilis ribosome. Mol. Microbiol. 52, 273-283. doi: 10.1111/j.1365-2958.2003.03972.x

Olsson, C. L., Graffe, M., Springer, M., and Hershey, J. W. B. (1996). Physiological effects of translation initiation factor IF3 and ribosomal protein L20 limitation in Escherichia coli. Mol. Gen. Genet. 250, 705-714. doi: 10.1007/s0043800 50124

Outten, C. E., and O'Halloran, T. V. (2001). Femtomolar sensitivity of metalloregulatory proteins controlling zinc homeostasis. Science 292, 24882492. doi: $10.1126 /$ science. 1060331

Panina, E. M., Mironov, A. A., and Gelfand, M. S. (2003). Comparative genomics of bacterial zinc regulons: enhanced ion transport, pathogenesis, and rearrangement of ribosomal proteins. Proc. Natl. Acad. Sci. U.S.A. 100, 9912-9917. doi: 10.1073/pnas.1733691100

Park, H. S., Ostberg, Y., Johansson, J., Wagner, G. H., and Uhlin, B. E. (2010). Novel role for a bacterial nucleoid protein in translation of mRNAs with suboptimal ribosome-binding sites. Genes Dev. 24, 1345-1350. doi: 10.1101/gad. 576310

Paul, B. J., Berkmen, M. B., and Gourse, R. L. (2005). DksA potentiates direct activation of amino acid promoters by ppGpp. Proc. Natl. Acad. Sci. U.S.A. 102, 7823-7828. doi: 10.1073/pnas.0501170102

Phan-Thanh, L., and Gormon, T. (1995). Analysis of heat and cold shock proteins in Listeria by two-dimensional electrophoresis. Electrophoresis 16, 444-450. doi: 10.1002/elps.1150160172

Piersimoni, L. (2010). Weird Facets of Ribosomes Synthesis in Stressfully Chilled Bacteria. Ph.D. thesis, University of Camerino, Camerino, MC.

Piersimoni, L., Giangrossi, M., Marchi, P., Brandi, A., Gualerzi, C. O., and Pon, C. L. (2016). De novo synthesis and assembly of rRNA into ribosomal subunits during cold acclimation in Escherichia coli. J. Mol. Biol. 428, 1558-1573. doi: 10.1016/j.jmb.2016.02.026

Pingoud, A., Gast, F. U., Block, W., and Peters, F. (1983). The Elongation Factor Tu from Escherichia coli, aminoacyl-tRNA, and guanosine tetraphosphate form a ternary complex which is bound by programmed ribosomes. J. Biol. Chem. 258, 14200-14205.

Pon, C. L., Paci, M., Pawlik, R. T., and Gualerzi, C. O. (1985). Structure-function relationship in Escherichia coli initiation factors. Biochemical and biophysical characterization of the interaction between IF-2 and guanosine nucleotides. J. Biol. Chem. 260, 8918-8924.

Potrykus, K., and Cashel, M. (2008). (p)ppGpp: Still magical? Annu. Rev. Microbiol. 62, 35-51. doi: 10.1146/annurev.micro.62.081307.162903

Potrykus, K., Murphy, H., Philippe, N., and Cashel, M. (2011). ppGpp is the major source of growth rate control in E. coli. Environ. Microbiol. 13, 563-575. doi: $10.1111 / j .1462-2920.2010 .02357 . x$

RajBhandary, U. L., and Chow, C. M. (1995). "Initiator tRNAs and initiation of protein synthesis," in tRNA: Structure, Biosynthesis, and Function, ed. D. Soll (Washington, DC: ASM Press), 511-528. doi: 10.1128/97815558183 33.ch25

Ramagopal, S., and Davis, B. D. (1974). Localization of the stringent protein of Escherichia coli on the 50 S ribosomal subunit. Proc. Natl. Acad. Sci. U.S.A. 71, 820-824. doi: 10.1073/pnas.71.3.820

Richter, D. (1980). Uncharged tRNA inhibits guanosine 3,5-bis (diphosphate) 3pyrophosphohydrolase [ppGppase], the spoT gene product, from Escherichia coli. Mol. Gen. Genet. 178, 325-327. doi: 10.1007/bf00270479
Rodnina, M. V., Malte Beringer, M., and Wintermeyer, W. (2007). How ribosomes make peptide bonds. Trends Biochem. Sci. 32, 20-26. doi: 10.1016/j.tibs.2006. 11.007

Rojas, A. M., Ehrenberg, M., Andersson, S. G., and Kurland, C. G. (1984). ppGpp inhibition of elongation factors Tu, G and Ts during polypeptide synthesis. Mol. Gen. Genet. 197, 36-45. doi: 10.1007/bf00327920

Samuel, C. E., D'Ari, L., and Rabinowitz, J. C. (1970). Evidence against the folatemediated formylation of formyl- accepting methionyl transfer ribonucleic acid in Streptococcus faecalis R. J. Biol. Chem. 245, 5115-5121.

Sankaran, B., Bonnett, S. A., Shah, K., Gabriel, S., Reddy, R., Schimmel, P., et al. (2009). Zinc-independent folate biosynthesis: genetic, biochemical, and structural investigations reveal new metal dependence for GTP cyclohydrolase IB. J. Bacteriol. 191, 6936-6949. doi: 10.1128/jb.00287-09

Severini, M., Spurio, R., La Teana, A., Pon, C. L., and Gualerzi, C. O. (1991). Ribosome-independent GTPase activity of translation initiation factor IF2 and of its G-domain. J. Biol. Chem. 266, 22800-22802.

Spurio, R., Brandi, L., Caserta, E., Pon, C. L., Gualerzi, C. O., Misselwitz, R., et al. (2000). The C-terminal subdomain (IF2 C-2) contains the entire fMettRNA binding site of initiation factor IF2. J. Biol. Chem. 275, 2447-2454. doi: 10.1074/jbc.275.4.2447

Spurio, R., Falconi, M., Brandi, A., Pon, C. L., and Gualerzi, C. O. (1997). The oligomeric structure of nucleoid protein H-NS is necessary for recognition of intrinsically curved DNA and for DNA bending. EMBO J. 16, 1795-1805. doi: 10.1093/emboj/16.7.1795

Stella, S., Spurio, R., Falconi, M., Pon, C. L., and Gualerzi, C. O. (2005). Nature and mechanism of the in vivo oligomerization of nucleoid protein H-NS. EMBO J. 24, 2896-2905. doi: 10.1038/sj.emboj.7600754

Toulokhonov, I. I., Shulgina, I., and Hernandez, V. J. (2001). Binding of the transcription effector ppGpp to Escherichia coli RNA polymerase is allosteric, modular, and occurs near the $\mathrm{N}$ terminus of the $\beta^{\prime}$-subunit. J. Biol. Chem. 276, 1220-1225. doi: 10.1074/jbc.m007184200

Travers, A. A., Debenham, P. G., and Pongs, O. (1980). Translation initiation factor 2 alters transcriptional selectivity of Escherichia coli ribonucleic acid polymerase. Biochemistry 19, 1651-1656. doi: 10.1021/bi00549a020

Tse-Dinh, Y. C., Qi, H., and Menzel, R. (1997). DNA supercoiling and bacterial adaptation: thermotolerance and thermoresistance. Trends Microbiol. 5, $323-$ 326. doi: 10.1016/s0966-842x(97)01080-9

Ueta, M., Wada, C., Bessho, Y., Maeda, M., and Wada, A. (2017). Ribosomal protein L31 in Escherichia coli contributes to ribosome subunit association and translation, whereas short L31 cleaved by protease 7 reduces both activities. Genes Cells 22, 452-471. doi: 10.1111/gtc. 12488

Ueta, M., Wada, C., and Wada, A. (2020). YkgM and YkgO maintain translation by replacing their paralogs, zinc-binding ribosomal proteins L31 and L36, with identical activities. Genes Cells 25, 562-581. doi: 10.1111/gtc.12796

Urlaub, H., Kruft, V., Bischof, O., Müller, E. C., and Wittmann-Liebold, B. (1995). Protein-rRNA binding features and their structural and functional implications in ribosomes as determined by cross-linking studies. EMBO J. 14, 4578-4588. doi: 10.1002/j.1460-2075.1995.tb00137.x

Van Bogelen, R., and Neidhardt, F. C. (1990). Ribosomes as sensors of heat and cold shock in Escherichia coli. Proc. Natl. Acad. Sci. U.S.A. 87, 5589-5593. doi: 10.1073/pnas.87.15.5589

Velasco, E., Wang, S., Sanet, M., Fernández-Vázquez, J., Jové, D., et al. (2018). A new role for Zinc limitation in bacterial pathogenicity: modulation of $\alpha$-hemolysin from uropathogenic Escherichia coli. Sci. Rep. 8, 6535-6546.

Vila-Sanjurjo, A., Schuwirth, B. S., Hau, C. W., and Cate, J. H. (2004). Structural basis for the control of translation initiation during stress. Nat. Struct. Mol. Biol. 11, 1054-1059. doi: 10.1038/nsmb850

Vimberg, V., Tats, A., Remm, M., and Tenson, T. (2007). Translation initiation region sequence preferences in Escherichia coli. BMC Mol. Biol. 8:100. doi: 10.1186/1471-2199-8-100

Vinogradova, D. S., Zegarra, V., Maksimova, E., Nakamoto, J. A., Kasatsky, P., et al. (2020). How the initiating ribosome copes with ppGpp to translate mRNAs. PLoS Biol. 18:e3000593. doi: 10.1371/journal.pbio.3000593

Wada, A. (1986a). Analysis of Escherichia coli ribosomal proteins by an improved two dimensional gel electrophoresis. I. Detection of four new proteins. J. Biochem. 100, 1583-1594. doi: 10.1093/oxfordjournals.jbchem. a121866 
Wada, A. (1986b). Analysis of Escherichia coli ribosomal proteins by an improved two dimensional gel electrophoresis. II. Characterization of four new proteins. J. Biochem. 100, 1595-1605. doi: 10.1093/oxfordjournals.jbchem. a121867

Wada, A., and Sako, T. (1987). Primary structures of and genes for new ribosomal proteins A and B in Escherichia coli. J. Biochem. 101, 817-820. doi: 10.1093/jb/ 101.3.817

Wada, A., Yamazaki, Y., Fujita, N., and Ishihama, A. (1990). Structure and probable genetic location of a "ribosome modulation factor" associated with 100 S ribosomes in stationary-phase Escherichia coli cells. Proc. Natl. Acad. Sci. U.S.A. 87, 2657-2661. doi: 10.1073/pnas.87.7.2657

Wang, D., Hurst, T. K., Thompson, R. B., and Fierke, C. A. (2011). Genetically encoded ratiometric biosensors to measure intracellular exchangeable zinc in Escherichia coli. J. Biomed. Opt. 16:087011. doi: 10.1117/1.3613926

Weber, M. H. W., and Marahiel, M. A. (2003). Bacterial cold shock responses. Sci. Progr. 86, 9-75. doi: 10.3184/003685003783238707

Wendrich, T. M., Blaha, G., Wilson, D. N., Marahiel, M. A., and Nierhaus, K. H. (2002). Dissection of the mechanism for the stringent factor RelA. Mol. Cell 10, 779-788. doi: 10.1016/s1097-2765(02)00656-1

Whyte, L. G., and Inniss, W. E. (2011). Cold shock proteins and acclimation proteins in a psychrotrophic bacterium. Can. J. Microbiol. 38, 1281-1285. doi: $10.1139 / \mathrm{m} 92-211$

Wienk, H., Tishchenko, E., Belardinelli, R., Tomaselli, S., Dongre, R., Spurio, R., et al. (2012). Structural dynamics of bacterial translation initiation factor IF2. J. Biol. Chem. 287, 10922-10932. doi: 10.1074/jbc.m111.333393

Winther, K. S., Roghanian, M., and Gerdes, K. (2018). Activation of the stringent response by loading of RelA-tRNA complexes at the ribosomal A-site. Mol. Cell 70, 95-105.e4.
Wu, L., and Welker, N. E. (1991). Temperature-induced protein synthesis in Bacillus stearothermophilus NUB36. J. Bacteriol. 173, 4889-4892. doi: 10.1128/ jb.173.15.4889-4892.1991

Yamagishi, M., de Boer, H. A., and Nomura, M. (1987). Feedback regulation of rRNA synthesis. A mutational alteration in the anti-Shine-Dalgarno region of the 16 S rRNA gene abolishes regulation. J. Mol. Biol. 198, 547-550.

Yamanaka, K. (1999). Cold shock response in Escherichia coli. J. Mol. Microbiol. Biotechnol. 1, 193-202.

Yang, X., and Ishiguro, E. E. (2001). Involvement of the N terminus of ribosomal protein L11 in regulation of the RelA protein of Escherichia coli. J. Bacteriol. 183, 6532-6537. doi: 10.1128/jb.183.22.6532-6537.2001

Zhang, Y., Burkhardt, D. H., Rouskin, S., Li, G. W., Weissman, J. S., and Gross, C. A. (2018). A Stress response that monitors and regulates mRNA structure is central to cold shock adaptation. Mol. Cell 70, 1-13.

Zuo, Y., Wang, Y., and Steitz, T. A. (2013). The mechanism of E. coli RNA polymerase regulation by ppGpp is suggested by the structure of their complex. Mol. Cell 50, 430-436. doi: 10.1016/j.molcel.2013.03.020

Conflict of Interest: The authors declare that the research was conducted in the absence of any commercial or financial relationships that could be construed as a potential conflict of interest.

Copyright (c) 2021 Cheng-Guang and Gualerzi. This is an open-access article distributed under the terms of the Creative Commons Attribution License (CC BY). The use, distribution or reproduction in other forums is permitted, provided the original author(s) and the copyright owner(s) are credited and that the original publication in this journal is cited, in accordance with accepted academic practice. No use, distribution or reproduction is permitted which does not comply with these terms. 